\title{
Sodium-Bearing Waste Treatment Applied Technology Plan
}

\author{
L. Lauerhass \\ V. C. Maio \\ S. K. Merrill \\ A. L. Olson \\ K. J. Perry
}

June 2003 
INEEL/EXT-03-00477

\title{
Sodium-Bearing Waste Treatment Applied Technology Plan
}

\author{
Lance Lauerhass \\ Vince C. Maio \\ S. Kenneth Merrill \\ Arlin L. Olson \\ Keith J. Perry
}

June 2003

Idaho National Engineering and Environmental Laboratory Idaho Falls, Idaho 83415

Prepared for the

U.S. Department of Energy

Assistant Secretary for Environmental Management

Under DOE Idaho Operations Office

Contract DE-AC07-99ID13727 


\section{ABSTRACT}

The Settlement Agreement between the Department of Energy and the State of Idaho mandates treatment of sodium-bearing waste at the Idaho Nuclear Technology and Engineering Center within the Idaho National Engineering and Environmental Laboratory. One of the requirements of the Settlement Agreement is to complete treatment of sodium-bearing waste by December 31, 2012. Applied technology activities are required to provide the data necessary to complete conceptual design of four identified alternative processes and to select the preferred alternative. To provide a technically defensible path forward for the selection of a treatment process and for the collection of needed data, an applied technology plan is required. This document presents that plan, identifying key elements of the decision process and the steps necessary to obtain the required data in support of both the decision and the conceptual design.

The Sodium-Bearing Waste Treatment Applied Technology Plan has been prepared to provide a description/roadmap of the treatment alternative selection process. The plan details the results of risk analyzes and the resulting prioritized uncertainties. It presents a high-level flow diagram governing the technology decision process, as well as detailed roadmaps for each technology. The roadmaps describe the technical steps necessary in obtaining data to quantify and reduce the technical uncertainties associated with each alternative treatment process. This plan also describes the final products that will be delivered to the Department of Energy Idaho Operations Office in support of the office's selection of the final treatment technology. 


\section{CONTENTS}

ABSTRACT

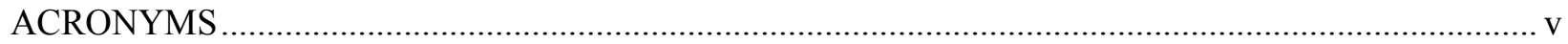

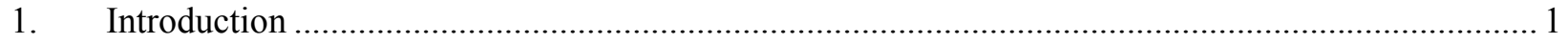

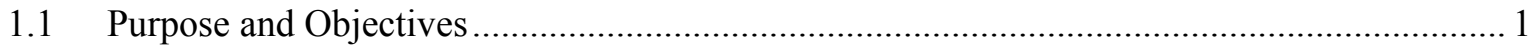

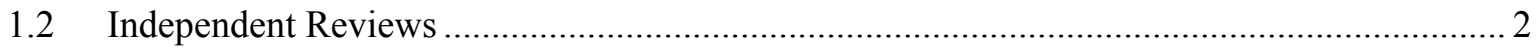

$1.3 \quad$ Treatment Technology Selection Strategy …............................................................. 2

1.4 Development Program Responsibilities and Integration............................................... 6

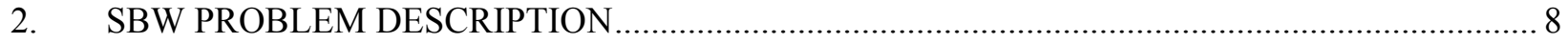

3. TECHNOLOGIES UNDER CONSIDERATION FOR TREATING SBW ................................ 9

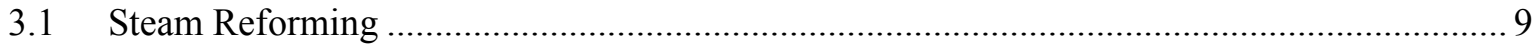

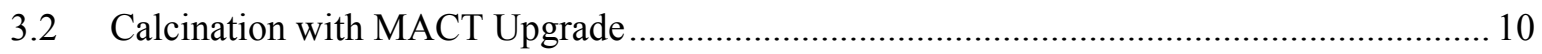

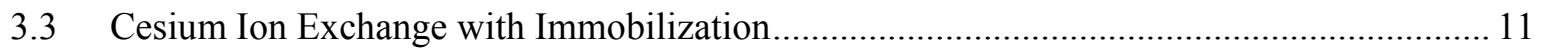

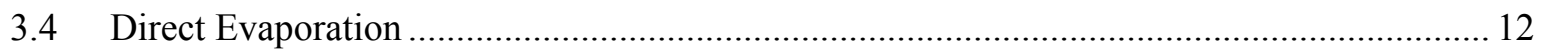

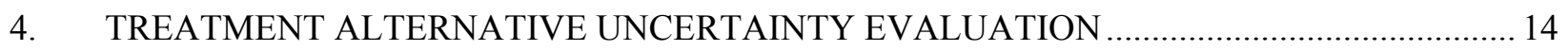

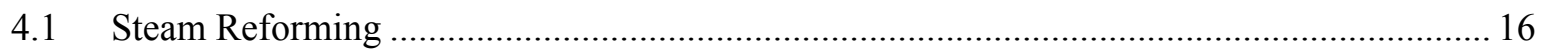

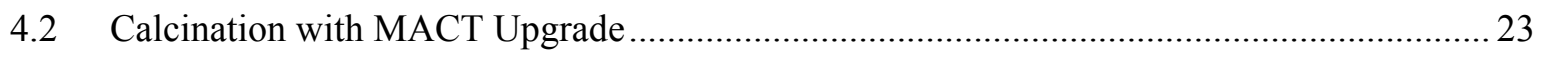

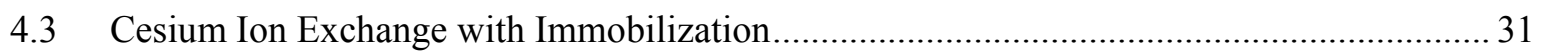

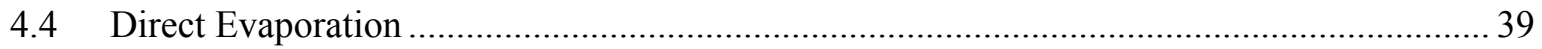

4.5 Uncertainties Common to Calcination, Steam Reforming, and Direct Evaporation (Wood

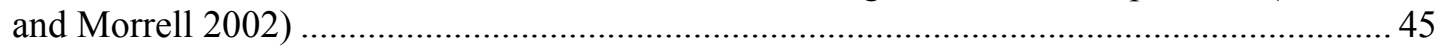

4.6 SBW Treatment Options —-Material Handling Considerations............................................ 45

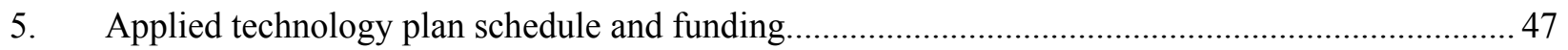

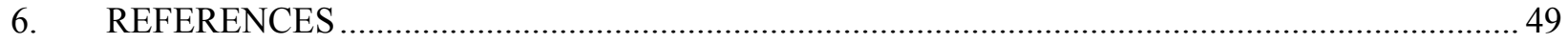




\section{ACRONYMS}

BBWI Bechtel BWXT Idaho, LLC

Btu British thermal unit

BWXT BWX Technologies, Inc.

CsIX cesium ion exchange

DOE-ID Department of Energy Idaho Operations Office

DQO data quality objective

EDF Engineering Design File

EXT external

GAC granulated activated carbon

HEPA high-efficiency particulate air (filter)

ICPP Idaho Chemical Processing Plant

INEEL Idaho National Engineering and Environmental Laboratory

INTEC Idaho Nuclear Technology and Engineering Center

LET\&D Liquid Effluent Treatment and Disposal (facility)

LLC Limited Liability Company

MACT maximum achievable control technology

NESHAP National Emissions Standards for Hazardous Air Pollutants

NGLW newly generated liquid waste

NWCF New Waste Calcining Facility

PDFs process flow diagrams

PSD particulate size distribution

RCRA Resource Conservation and Recovery Act

SAIC Science Applications International Corporation

SAR Safety Analysis Report

SBW sodium-bearing waste 
STAR Science and Technology Application Research (center)

TFF Tank Farm Facility

TRU transuranic

U.S. United States

WAC Waste Acceptance Criteria

WIPP Waste Isolation Pilot Plant 


\section{Sodium-Bearing Waste Treatment Applied Technology Plan}

\section{INTRODUCTION}

Sodium-bearing waste (SBW) disposition is one of the Department of Energy Idaho Operation Office's (DOE-ID) and State of Idaho's top priorities at the Idaho National Engineering and Environmental Laboratory (INEEL). The SBW Treatment Facility Project team has been working over the past several years to identify a treatment technology that meets DOE-ID and regulatory treatment requirements, including consideration of stakeholder input. As part of preliminary activities leading up to the selection of a treatment technology, this team has conducted two system trade studies. These studies resulted in the identification of four treatment alternatives to carry forward into conceptual design. The alternatives are (a) calcination with maximum achievable control technology (MACT) upgrade, (b) steam reforming, (c) cesium ion exchange (CsIX) with immobilization, and (d) direct evaporation. During Fiscal Year (FY) 2003 and early FY 2004, each alternative will be thoroughly evaluated under a technical review process to support a final technology recommendation.

The applied technology plan presents a summary of the remaining applied technology activities and prior process recommendation activities through September 2003. The SBW problem and the four alternatives are described in Section 2 and 3, respectively. Section 4 identifies the uncertainties resulting from technical and operational risk assessments. This section also addresses the steps required to resolve the uncertainties and the analysis needed to support the final recommendation. Individual technology roadmaps provide details of the logic and timing of each activity.

\subsection{Purpose and Objectives}

The purpose of this document is to identify information needed to enable the selection of a treatment technology for the SWB Treatment Facility. This involves the final selection of one technology from four alternatives using a method that is technically defensible. This plan:

- $\quad$ Defines the analytical and empirical studies that must be completed to provide DOE-ID with a SBW treatment process recommendation that is technically defensible (roadmap)

- $\quad$ Outlines the treatment alternative evaluation process

- Identifies development and testing plans that reduce technical risk and support basic data for conceptual design, permitting, and safety

- $\quad$ Provides technical linkages with the SBW Treatment Facility Project.

The plan provides DOE-ID a graphic roadmap of the ongoing program through the recommendation phase. The roadmap ties the contents of the plan to the overall project schedule and provides the project logic that defines all the steps from risk analysis to recommendation.

The objectives of this plan are to describe the key activities that technically frame each of the four alternatives. These key activities include:

- Using the results of the risk analysis for each alternative to provide a list of prioritized/ranked critical uncertainties - uncertainties prioritized high, moderate, or low 
- Identifying technical steps to quantify/resolve the uncertainties

- Identifying the testing required to clarify the uncertainties

- Identifying analytical and empirical processes to build a data set in support of the conceptual designs for each of the four alternatives.

The detailed work scope that delineates the specific test activities of each testing campaign will be described separately in test specifications and test plans for each of the four technologies.

This plan does not address any activities associated with conceptual design through fabrication and system checkout. The plan only addresses activities through the technology down-select process where data have been compiled and the analysis has been transmitted to DOE-ID.

This plan is a working document and will be modified and reviewed as required by DOE-ID or by discoveries made during the testing of the four alternatives.

\subsection{Independent Reviews}

To ensure the proper emphasis and staging of decision activities, an independent review-February 4-6, 2003 - was conducted of the proposed development process, including past and planned activities. The program will conduct further reviews as data are gathered and analyzed for each treatment alternative. Near the completion of the testing and data analysis phase, a final independent review will be conducted to ensure completeness prior to the release of a final report to DOE-ID. The independent team will also review the technology development plan for the primary recommended alternative.

The following were identified during the February review and recommended as areas to accelerate or emphasize to reduce technical risk to the project (Harmon et al. 2003):

- Identify level of risk associated with uncertainties for each alternative

- Clearly focus on high-risk technology uncertainties first in developing test activities

- $\quad$ Use technology roadmaps as tools to aid Department of Energy (DOE) management in making informed decisions at key decision points in the project.

\subsection{Treatment Technology Selection Strategy}

Numerous studies identifying treatment technologies for SBW have been completed since 1977 leading up to the current phase of choosing one alternative from the four that remain. These studies include an analysis in 1997 of a number of alternatives associated with the Idaho High-Level Waste and Facilities Disposition Environmental Impact Statement. In FY 2000, an alternatives analysis (Murphy, Palmer, and Perry 2000), reviewing nine technologies, was completed in support of the environmental impact statement. In early 2002, prior to the creation of the SBW Treatment Facility Project, another alternatives analysis (Murphy et al. 2002) was performed reviewing eight technologies. The most recent analysis, completed in September 2002 (Perry 2002), considered all the pervious alternatives and several new ones, including those suggested by a National Academy of Sciences committee. In all, 41 different technology alternatives were reviewed. Shown in Figure 1 are the steps of the September 2002 analysis, with Figure 2 presenting the remaining steps identified to complete the final selection of a treatment alternative by DOE Headquarters (DOE-HQ). Figure 2 identifies key activities to be initiated during the final phases of the treatment technology down selection process. These activities include: 
Establishing Selection Criteria: DOE Idaho Operations Office will include the treatment of sodium-bearing waste as part of the Idaho Completion Project/Idaho National Laboratory contract selection process, taking place during FY 2004 with execution beginning October 2004. The DOE Idaho Operations Office will develop the selection criteria in conjunction with the bid evaluation process.

Complete Technical Risk Assessments and Prioritize Technical Uncertainties: As part of the SBW Treatment Facility Project risk management process each uncertainty is analyzed in a structured, stepwise methodology based on DOE's Project Management Practice 8 (DOE 2000b) and INEEL GDE70, Section XIII, Project Risk Management (INEEL2000) and Guidelines for Project Technical Risk Management (INEEL 2001). The analysis results in a priority level; high, moderate, or low, assigned to the technical uncertainty allowing the SBW applied technology and process engineering teams to assign funding and establish a development schedule. All high and moderate-level uncertainties will be addressed in a testing and evaluation phase. Low-level uncertainties will be addressed if they do not affect cost and schedule and can be resolved as a natural adjunct to the test.

Data Requirements and Test Plans: Each alternative is analyzed determining what data are required to resolve the identifies uncertainties, test plans are generated from these data requirements, and each test plan is reviewed internally by an independent review group to assure that the data are what is required and that the test will produce the data.

Testing and Data Analysis: Testing will either be conducted internal to the INEEL or will be subcontracted, as with steam reforming. Data reports will be provided by the testing team with limited analysis, further analysis will be completed by the applied technology and processing engineering teams. If the data analysis identifies data deficiencies, recommendation will be made to execute additional test if the deficiency cannot be resolved analytically.

Data Analysis and Document Results: A final report will be delivered to the DOE Idaho Operations Office providing a summary of the testing and data derived from the tests as they apply to the identified technical uncertainties. All supporting data will also be made available to DOE.

Final Products and Recommendation: The DOE Operations Office will select a subcontractor to treat the sodium-bearing waste as part of the Idaho Completion Project bid process. Data generated either by or for Bechtel BWXT Idaho, LLC during the alternative treatment technology evaluation phase, fiscal years 2003 and 2004, will be analyzed, documented and discussed with the DOE Idaho Operations Office. These data documented in a final report will be transmitted to the DOE Idaho Operations Office to be used in their contract selection process. The selected contractor will begin their execution of the SBW program starting October 2004. 


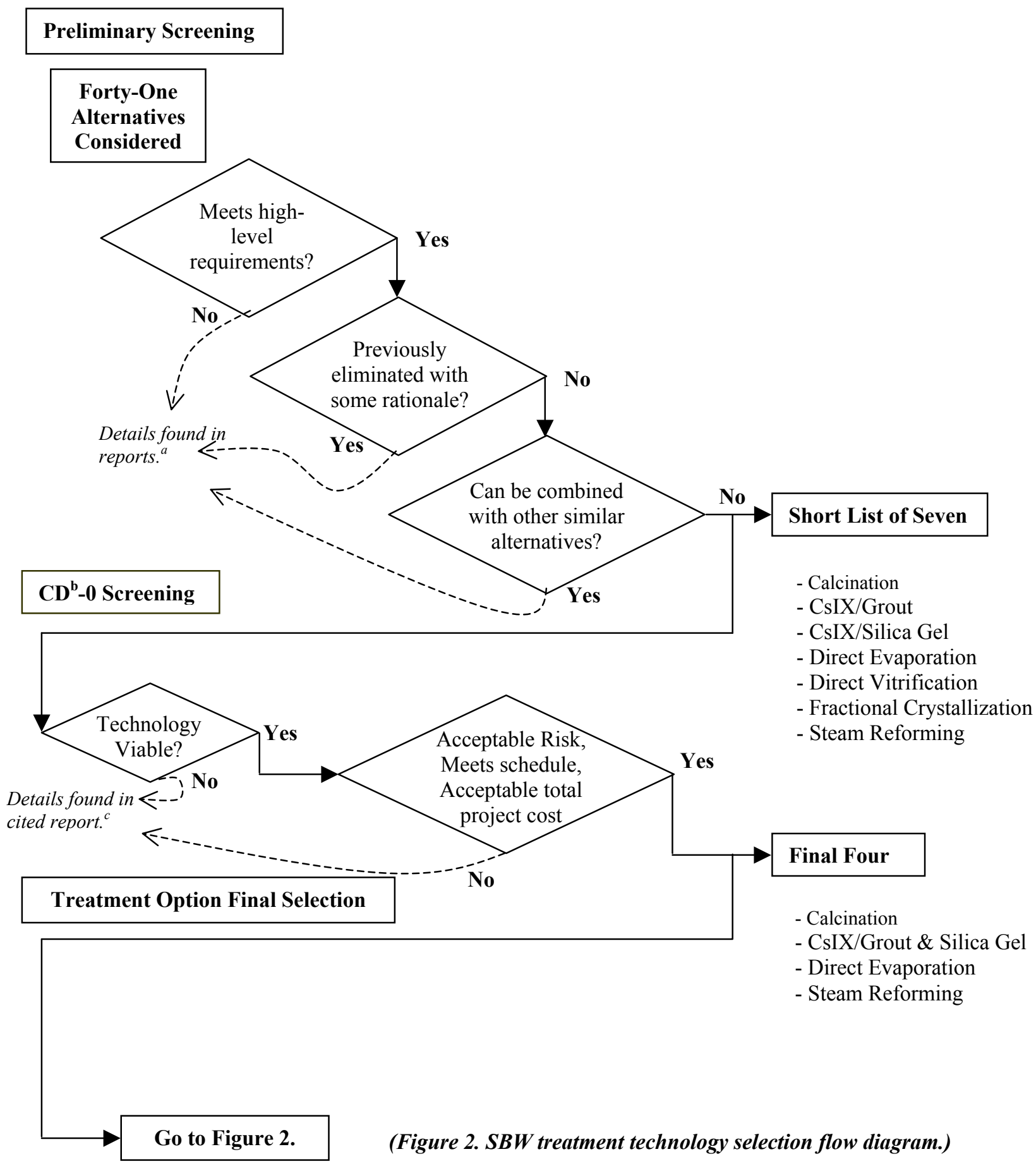

\begin{tabular}{c|c|}
$\begin{array}{c}\text { Forty-One } \\
\text { Alternatives } \\
\text { Considered }\end{array}$ \\
CD ${ }^{\mathbf{b}-0}$ Screening \\
\hline Treatment Option Fin \\
Viable?
\end{tabular}

a. Murphy, Palmer, and Perry 2000; Murphy et al. 2002; and Perry 2002.

b. Critical decision.

c. Perry 2002.

Figure 1. SBW treatment screening and selection flow diagram. 


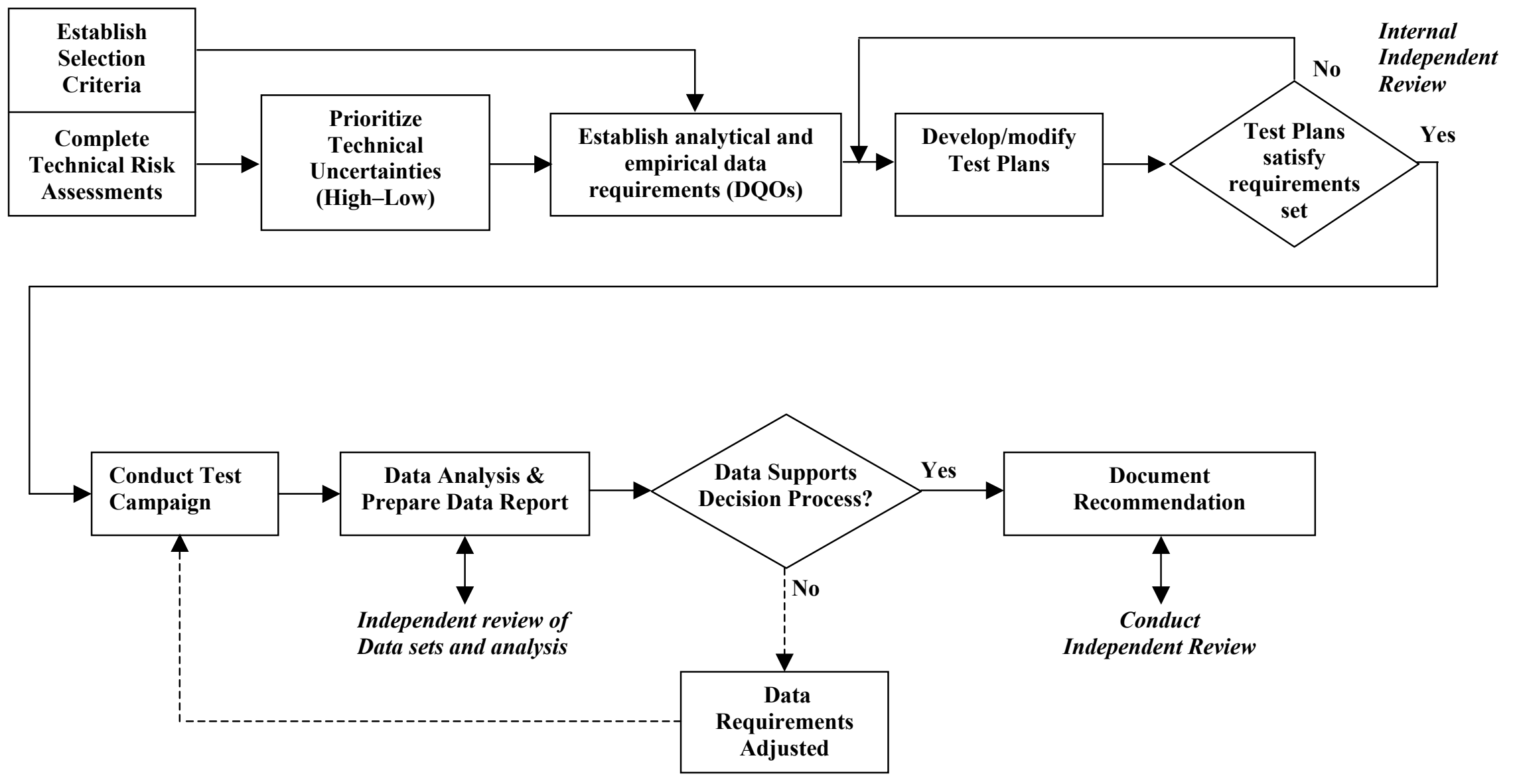

Figure 2. SBW treatment technology final selection flow diagram. 
This document addresses the applied development work associated with the identified technical uncertainties that will impact the technology selection. DOE has made the decision to include the treatment of the SBW as part of the Idaho Completion Project subcontract process. The subcontract we be solicited, reviewed, and placed during fiscal year 2004. DOE is responsible for that technology selection, and officials of the department will develop a separate document detailing the selection process and how that recommendation will be made by DOE-ID to DOE-HQ. The document explains the criteria that will be used and the sources of data that will be employed in arriving at a recommendation. This applied technology development plan will be a source of data used in the decision-making process.

\subsection{Development Program Responsibilities and Integration}

Process technology development is required by the SBW Treatment Facility Project to technically define the treatment options and to resolve technical risks and uncertainties. This process design function is accomplished by the Process Technology Development organization and then is translated into process and instrument diagrams by the Engineering organization and then into a facility design for construction.

The Process Technology Development organization fulfills both Process Engineering and Applied Technology functions (Olson 2003).

Process Engineering is responsible for classical process design. This includes assimilating process technical requirements, synthesizing flow sheets of process operations, selection of operating conditions, preliminary selection and sizing of appropriate equipment, and simulation of the process. These activities result in process flow diagrams, mass and energy balances, process descriptions, process stream summaries for individual alternatives, and utility requirements. Process flow diagrams and preliminary equipment sizing are required for the Engineering organization personnel to develop facility layouts and cost estimates. Tradeoff studies are performed to optimize configuration alternatives. As the process design is prepared, it may be necessary to make assumptions that have not been validated on a scientific basis. An example is the fate of a specific component in a unit operation. Initially, an assumption must be made as to its split between unit operation outputs. This is a design basis assumption that must be scientifically validated prior to actual operation. Process Engineering must assemble these design bases and update them as data validating the bases become available.

Applied Technology is responsible for performing the appropriate laboratory and pilot scale testing to scientifically validate individual unit operations and integrated processes. This is related to the design bases as assembled by Process Engineering. Applied Technology must validate each process design basis assumption generated by Process Engineering before final design of the selected treatment option. Applied technology will design experiments, procure and fabricate experimental equipment, generate experimental test plans, gather experimental data, analyze the data, and generate reports that validate the process design assumptions. Mathematical/empirical models of unit operations and physical properties data are needed to perform integrated process flow sheet simulations. Applied technology will develop and validate these products for Process Engineering use.

The major interface for the Project between Process Technology Development and Engineering occurs at Process Engineering. Functionally, Process Engineering must define the process by developing process flow diagrams, process descriptions, and performing mass balance calculations. This is accomplished by assembling process requirements from Systems Engineering and gathering existing technical data. The baseline product (process designs for each treatment option) has been summarized in

Engineering Design File (EDF)-2373 (Barnes, Wood, and O'Brien 2002). The baseline is provided to Engineering and is the basis for developing process and instrument diagrams. Comments and suggestions received back from Engineering, requiring further technical data for implementation, are transmitted back to Process Technology Development. 
Many other functional interfaces are required in support of Process Technology Development. Two of these functional support organizations are:

- $\quad$ Procurement providing administration of subcontracts and the purchase of materials and supplies

- $\quad$ Environment, Safety, Health, and Quality Assurance ensuring that the safety and health of workers is maintained during the performance of experimental work, quality assurance according to company and project plans is maintained, and data required for permitting activities are obtained using approved policy and procedures. 


\section{SBW PROBLEM DESCRIPTION}

Radioactive liquid waste has been generated over the last five decades at the Idaho Nuclear Technology and Engineering Center (INTEC), formerly called the Idaho Chemical Processing Plant (ICPP), as a result of nuclear fuel reprocessing activities. From December 1963 until June 2000, the Waste Calcining Facility and the New Waste Calcining Facility (NWCF) processed the liquid waste into a granular, solid form. As of October 31, 2002, approximately 1,005,000 gallons of waste remained in tanks at the tank farm. Approximately $17 \%$ of the total waste presently in the tank farm is dilute waste that will be concentrated in future high-level waste evaporator campaigns. Additional liquid waste will be generated in the future as a result of filter leach operations, equipment and building decontamination activities, Resource Conservation and Recovery Act (RCRA) closure activities, and other operations at INTEC.

A SBW treatment facility will treat liquids and solids contained in existing tanks at the INTEC. The treatment facility may also treat additional liquid waste, called Newly Generated Liquid Waste (NGLW) that will be generated after 2005 and stored in separate tanks from the SBW.

A complete description of the feed composition for the SBW treatment process can be found in report INEEL/EXT-2000-01378, Revision 2 (Barnes and Millet 2003). This report presents the most recent compilation of volumes and compositions of the feed streams to the four proposed alternative treatment processes. These liquid wastes have been stored in eleven 300,000-gallon underground tanks at INTEC. The underground tank facility at INTEC is referred to as the Tank Farm Facility (TFF).

Tanks WM-180 and WM-189 presently contain volumes of waste near their administrative capacities and no additions to these tanks are expected. As of November 30, 2002, Tank WM-188 contained about 210,000 gallons of waste. Approximately 75,000 gallons of additional waste will be added to Tank WM-188 prior to the start of treatment. The compositions report for waste in Tanks WM-180 and WM-189 is based on sample analyses; the composition of waste in tank WM-187 and WM-188 is based on analyses of source streams, calculations using plant evaporator operations information, and simulation of expected future evaporation of dilute wastes

As tanks in the TFF are flushed and closed, solids will accumulate in Tank WM-187. The treatment process will process the solids in this tank as well as solids from the three SBW tanks (WM-180, WM-188, WM-189). Compositions are defined both for alternatives that process solids separately and together with SBW liquid.

Fewer data are available for tank solid compositions and quantities than for SBW liquid compositions and quantities. Compositions of solids are based on samples from four TFF tanks (WM-180, WM-182, WM-183, and WM-188).

Projections have been made of the volumes of NGLW streams generated prior to and during operation of the SBW treatment facility. For some of these NGLW streams, chemical composition data are available and have been used in generating treatment facility feed compositions. However, data for radionuclide concentrations in NGLW are extremely limited. Thus, radionuclide concentrations in treatment facility feeds are based solely on data from existing tank waste. Starting in FY 2006, NGLW will be collected in Tanks WM-100, WM-101, and WM-102. The accumulated NGLW may later be blended with SBW for treatment in the SBW treatment facility. 


\section{TECHNOLOGIES UNDER CONSIDERATION FOR TREATING SBW}

Four treatment processes have been identified that are capable of satisfying the requirements for the SBW Treatment Facility Project. A brief description of each of these processes is provided below. Process flow diagrams (PDFs) for each of the four treatment alternatives are included in the Appendix. These PDFs were the basis for the generation of this development plan. Over the course of the evaluation process and based on experimental results, the PDFs will be modified to reflect more efficient and cost effective configurations for processing the sodium-bearing waste. The PDFs are not reflective of any final recommendation.

\subsection{Steam Reforming}

Steam reforming would convert liquid and solid tank waste to a dry solid product, using a fluidized bed reactor that utilizes non-oxidizing gas, such as steam or $\mathrm{CO}_{2}$ as the fluidizing gas. The waste product would be shipped to the Waste Isolation Pilot Plant (WIPP) as remote-handled waste. Tank liquid and solids would be co-processed in the reformer.

Chemical additives would be required to successfully process the SBW and solids in the reformer. A reductant would be added to the feed batch that would react with water in the steam reformer to produce $\mathrm{CO}$ and $\mathrm{H}_{2}$, thus producing a reducing environment to promote waste denitration and $\mathrm{NO}_{\mathrm{x}}$ destruction. A dry additive feed system would also be required. This system would consist of additive bins and feeders that would feed into the solid additive chute.

The steam reformer is a fluidized bed reactor in which non-oxidizing gas would enter through the plenum in the bottom of the vessel, and routed through a fluidizing grid into the main section of the reactor. A bottom product withdrawal port would be included to remove large agglomerates and/or product from the reactor. In the middle reactor section, bed media and solid product would be fluidized. Waste feed slurry would be pumped through a nozzle into this section of the bed. Also, solid additives would be fed into this section of the reactor. Indirect heating may be required to maintain reactor temperature. The upper section of the reactor is wider in diameter than the middle section, resulting in reduced gas velocity that would cause the larger entrained solid particles to disengage from the gas stream and flow back into the reaction zone of the reactor. Oxygen could be injected in the upper portion of the reactor to react with $\mathrm{H}_{2}$ and $\mathrm{CO}$ to reduce the $\mathrm{H}_{2}$ and $\mathrm{CO}$ concentrations exiting the reactor to below the lower explosive limits.

Solid product would be removed from the reformer via two separate methods. Fine particulate would be carried out the top of the reactor with the off-gas. A cyclone separator would be used to separate large particulate from the fluidization gas, and the large particulate would be gravity fed from the bottom of the cyclone back into the bed reaction zone of the reformer. Additional particulate would be separated from the off-gas using a ceramic filter. The filter would be back-pulsed with air periodically, causing the solid filter cake to drop to the bottom of the filter housing. A rotary valve would be positioned below the filter housing to feed the product to a screw cooler/conveyer prior to product collection and packaging.

Solid product could also be removed from the reformer through the bottom withdrawal system. The reformer plenum would be cone shaped, allowing this section of the reactor to function like a bin. A high-temperature rotary valve beneath the plenum would meter solid product (and any agglomerates that form in the bed) to the product screw cooler/conveyer. Product from the screw cooler would be metered into a pneumatic transfer system to the bottoms product collection bin using a rotary valve. Collected product would be metered into canisters using a loss-in-weight feeder. The canister loading station would be positioned on a vibratory table to aid in product settling and densification of the product. 
Off-gas from the ceramic filter would be quenched in a spray quench tower. Quench liquid would be supplied from a quench tank using a quench pump. Off-gas from the quench tower would pass through a demister built into the upper portion of the quench tower before being routed to a venturi scrubber. A dilute caustic solution $(\sim 0.2 M)$ would be added to the scrub tank to maintain the scrub solution at a $\mathrm{pH}$ of 8.0. Caustic would react with acid vapors in the off-gas $\left(\mathrm{HCl}, \mathrm{HF}, \mathrm{HNO}_{3}\right)$ to more effectively scrub these constituents in order to meet the MACT emissions limit for $\mathrm{HCl}$ and reduce corrosion in the off-gas system lines and equipment.

The quench tower and venturi scrubber would remove the majority of particulate and acid from the off-gas. A portion of the water in the off-gas stream would then be condensed to provide sufficient make-up liquid for the quench, scrub, and mist elimination unit operations. Following the condenser, the off-gas would be routed to a high-efficiency mist eliminator. The purpose of the eliminator is to remove sub-micron particulate not captured in the quench or scrubbing operations, thus serving as a final particulate guard prior to high-efficiency particulate air (HEPA) filtration.

Following the wet gas cleaning operations, the off-gas would undergo further treatment to remove fine particulate and mercury, and also destroy residual hydrocarbons and CO. The first step in the dry off-gas cleaning train is to reheat the gas above the dew point. The off-gas would then be routed to an electrically heated thermal oxidizer to destroy residual $\mathrm{H}_{2}, \mathrm{CO}$ and hydrocarbons. In order to adequately oxidize these components, a temperature of $1000^{\circ} \mathrm{C}$ would be required. Lower temperatures may not result in complete oxidation, while higher temperatures can lead to thermal $\mathrm{NO}_{\mathrm{x}}$ formation. The off-gas from the thermal oxidizer will be rapidly quenched to $105^{\circ} \mathrm{C}$ in a quench tower. The quench tower would include a mist eliminator in the upper section to minimize droplet carryover into a reheater and then into the granulated activated carbon (GAC) beds.

Sulfur-impregnated granulated activated carbon beds would be used to remove mercury from the off-gas in order to comply with the MACT emissions limit of $45 \mu \mathrm{g} / \mathrm{dsm}^{3}$. Two beds will be utilized, and the piping configuration will allow the flexibility of parallel or series operation with either bed in the front position. Following mercury removal, the gas will be routed to final HEPA filters.

\subsection{Calcination with MACT Upgrade}

The NWCF operated from 1982 to 2000 processing liquid waste from the TFF. To process SBW in the NWCF, supplemental equipment would be needed to reduce the air emissions to meet MACT limits, package calcine into waste canisters for disposal at WIPP, and possibly treat a small amount of scrub solution into a final waste form.

Mixing pumps would be installed in several TFF tanks to mix solids that have settled to the bottom of the tanks with the bulk SBW liquid. Existing steam jets would transfer the SBW liquid/solids mixture to the NWCF blend and hold cell tanks. Aluminum nitrate would be added to the calciner feed to avoid agglomeration in the bed that would otherwise be caused by the formation of low-melting alkali nitrates. Calcium nitrate would be added to the feed to control fluoride volatility by forming the insoluble and high-boiling $\mathrm{CaF}_{2}$, thus helping to control fluoride-induced corrosion in the calciner and off-gas treatment train. A portion of the off-gas scrub solution would also be blended with the feed in order to minimize secondary waste and reduce corrosion in the scrub system.

Fluidizing air is preheated prior to entering the calciner. In the middle section of the calciner, bed media and solid product are fluidized. Dolomite is initially charged to the bed, but as operation proceeds, calcine product replaces the dolomite as the bed media. Waste feed slurry is pumped through a nozzle into this section. Also, kerosene and oxygen are metered into this section of the bed to facilitate in-bed combustion to maintain the operating temperature of $600^{\circ} \mathrm{C}$. In this zone, water, nitric acid, and some 
volatile species are volatilized, leaving metal salts called "calcine." Kerosene combustion also generates $\mathrm{CO}_{2}, \mathrm{H}_{2} \mathrm{O}$ and products of incomplete combustion. The upper portion of the reactor, larger in diameter, reduces gas velocity that in turn causes larger entrained solid particles to disengage from the gas stream and flow back into the reaction zone.

A cyclone separator would separate particulate from the fluidization gas, with the particulate falling into a fines column, and then into a pneumatic transfer line. The majority of the solid product would be removed from the calciner through the side withdrawal system. Withdrawn calcine would flow into the same pneumatic transfer line used for fines transport, thus transporting both the primary product and the fines product to the load-out bin. Product collected in the load-out bin would be metered into canisters using a loss-in-weight or volumetric feeder.

Volatile acids and salts and fine particulate that pass through the cyclone separator would be collected in the off-gas cleaning wet unit operations. Off gas from the cyclone would be quenched using a quench spray tower. Off gas from the quench tower would be routed to a variable-throat venturi scrubber. The venturi scrubber provides intimate contact of the liquid and gas to "scrub" particulate and semi-volatile material from the gas. Off gas exiting the scrubber would be routed to a knock out drum to separate liquid from the gas stream. Quench and scrub liquid would be pumped from a common tank. A scrub cooler is located downstream of the scrub pump to allow control of the scrub build-up rate.

The quench tower and venturi scrubber would remove the majority of particulate from the off gas. A mist eliminator is located downstream of the scrubber knock out drum to capture any liquid carryover from the quench/scrub system. When the NWCF was originally designed, it was anticipated that ruthenium would exist as a volatile species. Silica gel adsorbers were placed downstream of the mist eliminator for this purpose but now serve only as a filter. A second mist eliminator is located downstream of the adsorbers to remove any water droplet carryover from the adsorbers.

Following the wet gas cleaning operations, the off gas would undergo further treatment to remove fine particulate and mercury, and to destroy $\mathrm{NO}_{x}, \mathrm{CO}$, and total hydrocarbons. The first step in the dry off gas cleaning train would be to reheat the gas above the dew point prior to HEPA filtration. Heating would be accomplished using an existing heater. Following the reheater, the off gas would be HEPA filtered prior to leaving the hot cell. The off gas would then be routed to new equipment for additional treatment to meet MACT emissions limits. The first treatment step would be a multi-stage combustor to destroy $\mathrm{NO}_{\mathrm{x}}, \mathrm{CO}$, and residual hydrocarbons. Following multi-stage combustion, quench water would be injected to cool the gas to $110^{\circ} \mathrm{C}-140^{\circ} \mathrm{C}$.

A mist eliminator would be placed downstream of the multi-stage combustor final quench to remove liquid carryover followed by a reheater. Sulfur-impregnated granulated activated carbon beds would be used to remove mercury and $\mathrm{HCl}$ from the off gas in order to comply with the MACT emissions limit of $45 \mu \mathrm{g} / \mathrm{dsm}^{3}$. Multiple beds would be utilized, and the piping configuration would allow the flexibility of parallel or series operation of these beds. Following mercury removal, the gas would be routed to final HEPA filters. Exhaust from the off-gas train would be monitored via a continuous-emissions monitoring system prior to venting to the atmosphere through the stack.

Treatment and disposal options for off-gas treatment scrub purge are being evaluated. This waste stream could be grouted, or possibly added with no or minimal treatment to the calcine product.

\subsection{Cesium lon Exchange with Immobilization}

The CsIX/transuranic (TRU) grout process converts liquid SBW into a contact-handled, solidified waste that would meet DOT/NRC transportation requirements to WIPP, as well as, Waste Acceptance 
Criteria (WAC) for disposal at WIPP. Solids that are entrained in the liquid waste would be separated, combined with other solids that have settled to the bottom of TFF tanks and processed separately into a remote-handled TRU waste that meets WIPP WAC.

Liquid SBW would be transferred from TFF tanks by existing steam jets to a receiving tank and processed to remove the bulk of the radioactivity via a cesium (Cs) ion exchange column. The liquid SBW would be filtered through a cross flow process, neutralized, passed through ion exchange columns and then grouted. Separated solids would be transferred from the TFF tanks to a solids decant tank in the treatment facility and processed intermittently over the same period as the liquid SBW.

For the solidified SBW to be contact handled, dissolved ${ }^{137} \mathrm{Cs}$ and solid particles, because they contain ${ }^{137} \mathrm{Cs}$, must be removed from the liquid tank waste. Dissolved cesium would be removed by ion exchange. Cesium removal efficiencies of $99.9 \%$ have been demonstrated with SBW simulant in small-scale ion exchange tests. Assuming an ion exchange removal efficiency of $99.9 \%$ for the full-scale treatment facility and the average SBW composition, a solids removal efficiency of greater than $92.5 \%$ would be required to ensure that the grouted SBW has a surface dose rate less than the contact-handled limit of $200 \mathrm{mrem} / \mathrm{hr}$. Removal of cesium by ion exchange results in a secondary waste of spent ion exchange sorbent that must be treated and packaged for WIPP transport and disposal as a remote-handled transuranic waste.

The ion exchange effluent would be grouted to meet the WIPP limit on free liquid in waste containers. A high waste loading in the grout is desired in order to minimize treatment equipment, materials and disposal costs. Calcium hydroxide would be added prior to the other grouting ingredients to neutralize the acid in the waste that could prevent the grout from setting. Calcium hydroxide would be added in two steps to provide temperature control of heat generated in the acid neutralization reaction.

An alternative to grouting the ion exchange effluent is also being evaluated. Absorption of the cesium-free liquid waste on a material such as silica gel may result in a mechanically simpler operation. The costs and benefits of this option will be determined in order to select between the grouting and absorption options.

Tank solids would be slurried from TFF tanks to a solids collection and decant tank containing the permeate solids from the cross flow filtration upstream of the Cs IX column. After partial concentration by settling the slurry will be pumped through a caking filter. At the end of a filtration cycle, the filter cake would be washed, then dried using steam and/or heated air. The dried solids would then be pulsed off the filter and packaged in canisters for disposal at WIPP as remote-handled transuranic waste.

\subsection{Direct Evaporation}

The direct evaporation process would convert the SBW into a solidified remote-handled TRU waste that meets both DOT/NRC transport and WIPP WAC. This simple, low temperature process involves evaporating water and acid in the liquid SBW waste to the point that upon cooling, the evaporator bottoms would completely solidify, thus meeting the WIPP limit for free liquids. The evaporator(s) would need to be operated under a vacuum ( $\sim 4$ psi vacuum) to keep the boiling endpoint less than $125^{\circ} \mathrm{C}$ for safety reasons. A small layer of silica gel would be added to the top of each waste canister to prevent the sodium nitrate in the solidified waste from reabsorbing moisture from the air while the canisters are vented.

Evaporation of SBW would remove water and nitric acid from the waste, along with small amounts of other volatile species such as mercury, hydrochloric acid, and entrained solids. Various methods could be used to treat the evaporator off-gas into disposable low-level mixed waste products. One method 
would be to condense the off-gas, process the condensate in existing INTEC evaporation and distillation equipment and then grout the small volume of remaining concentrated acid.

To minimize corrosion of the evaporator condensate due to ppm levels of hydrofluoric acid, aluminum nitrate would be added to complex the hydrofluoric acid. The condensate would then be transferred to the INTEC process equipment waste evaporator and liquid effluent treatment and disposal (LET\&D) systems to be concentrated. The resulting nitric acid, 12 molar, would then be neutralized and grouted. Due to the listed waste codes associated with the tank farm SBW, the nitric acid is expected to be listed waste and therefore will require stabilization and disposal at a mixed waste disposal facility, such as Hanford or Envirocare of Utah.

In the direct evaporation process, tank solids could either be processed separately or together with the SBW liquid. If processed separately, the tank heel flush slurry would be processed simultaneously with liquid SBW but in different and parallel equipment. The heel slurry would be filtered, with the filtrate water being sent to the existing process equipment waste evaporator. The solids collected on the filter would be dried and packaged for disposal at WIPP as remote-handled waste. Processing the solids with the SBW through the evaporator would eliminate this solids processing equipment and resulting waste stream, but would add marginally to the volume of solidified SBW wastes and may affect the type of evaporator required. Tests are planned to confirm the feasibility of co-processing the solids. 


\section{TREATMENT ALTERNATIVE UNCERTAINTY EVALUATION}

Section 4 identifies the uncertainties for each of the four treatment technologies. These uncertainties result from the technical and operational risk assessments. The section addresses the testing and development steps required in resolving the uncertainties and required analysis needed to support the final recommendation. Individual technology roadmaps provide details of the logic and timing of each treatment alternative.

The four alternatives presented for treating SBW are the result of a logical decomposition of the overall SBW Treatment Facility mission. That mission is to treat the SBW and dispose of it at an appropriate repository. That mission is further defined by the High-Level Waste and Facilities Disposition Environmental Impact Statement, which states that the preferred treatment method is immobilization and the preferred repository for this waste is WIPP. These statements regarding the mission of the SBW treatment project are significant to the development of the methods for treating the SBW.

SBW includes both RCRA and radioactive constituents, meaning that its treatment has to meet all applicable RCRA and National Emissions Standards for Hazardous Air Pollutants (NESHAP) requirements. The added mission definition of disposal at WIPP applies the waste product requirements associated with the WIPP Waste Acceptance Criteria as well as any safety requirements driven by the Safety Analysis Reports (SARs) for the use of WIPP transportation packages. In order to immobilize this waste, certain chemical processes must be performed. Those chemical processes have technical and functional requirements that result from the WIPP WAC, RCRA, and NESHAP regulations, or other safety requirements associated with such chemical processes. As all processes produce some air emissions, these processes must meet any applicable air emissions requirements (e.g., MACT). Figure 3 gives an example of how the functional breakdown of the SBW mission leads to an understanding of the treatment requirements.

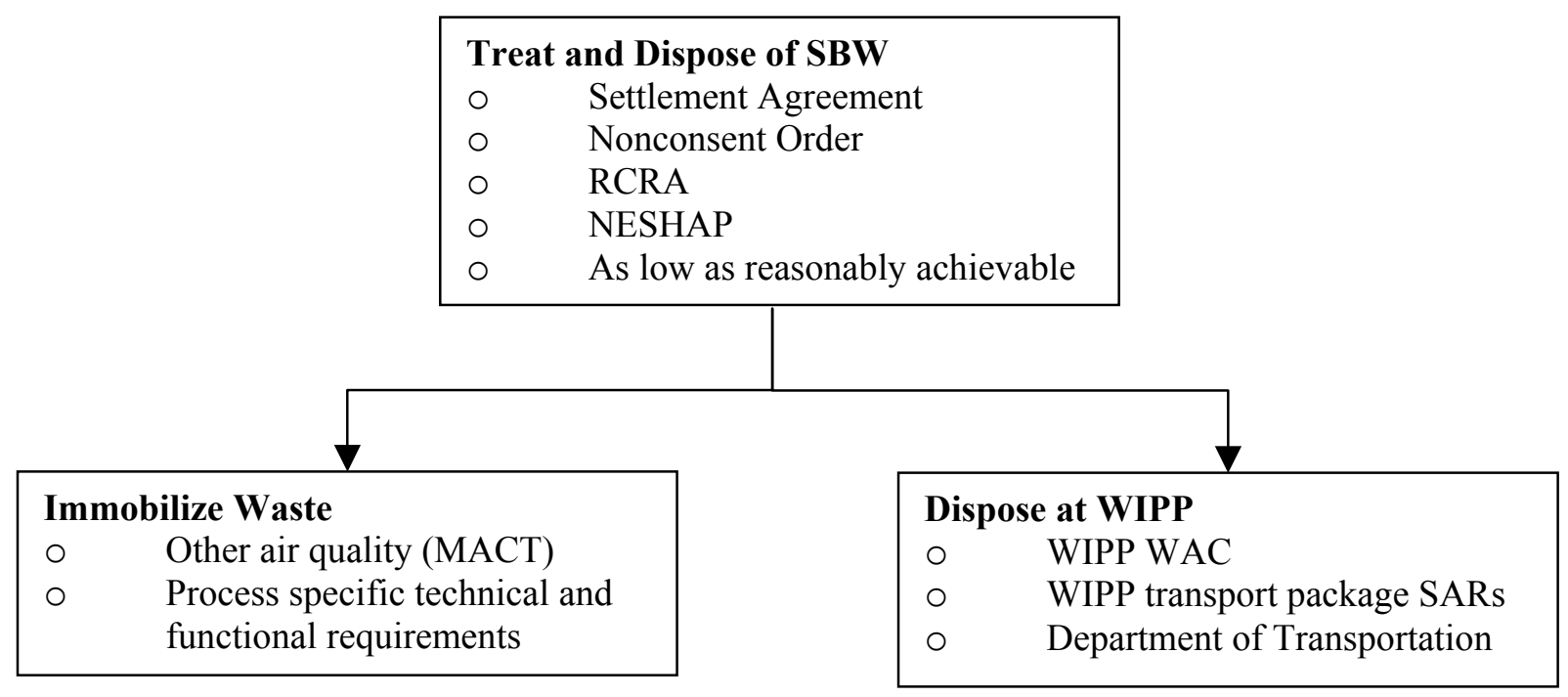

Figure 3. Partial decomposition of the mission of SBW treatment and disposal and some applicable requirements.

Once the functions were decomposed to a low enough level, treatment methods were selected that meet the given requirements. Each treatment method was proposed as a way of accomplishing the function of immobilizing this waste. Each has its own advantages and disadvantages relative to meeting the requirements associated with immobilization and the higher-level requirements of treating SBW. 
After these treatment methods were proposed, the technical and functional requirements of each were derived relative to meeting the overall requirements of immobilizing the waste.

For each of the four treatment alternatives technical uncertainties have been identified regarding how some of the methods meet the individual treatment requirements. These uncertainties, once they are assessed for both their probability and consequence, are defined as risks. The risks associated with each alternative being able to treat the SBW waste to the point where the waste product and the actual treatment process meet the defined requirements need to be addressed so that the final facility and process will have acceptable risk. To accomplish this end objective the risks are prioritized by combining their probability and consequence into a risk factor. The Risk Management Plan for the SBW Treatment Facility Project defines how this process is implemented. Risk is a dimension of technical uncertainty and an important consideration in establishing prioritized sequencing of development activities. The priority of technical uncertainties is defined as one of three separate categories: high $(H)$, moderate $(M)$, and low $(L)$.

A risk management team has prioritized each technical uncertainty identified in this plan and the extent and depth of the recommended development activities have been established based on this assessment. The priority of the uncertainty is listed following the title. An example would be Product Characterization $(H)$.

Not every risk, requirement, or uncertainty is addressed in this plan. Resource and schedule limitations require that the highest risks be worked first. Risks that are classified as "low" are requirements that have a very high probability of being met and are not addressed at this time unless they are an adjunct of a high risk uncertainty and it is cost and time effective to do so during initial testing of the associated high-priority uncertainty. Since each requirement must be addressed at some point, work will need to be identified to address these requirements. This plan is meant only to define the work necessary to support a well-founded alternative decision that DOE will be making in the next year. To that end, it is vital to show which alternatives are viable, how long they will take to treat the waste, and how much that treatment will cost. Such metrics can only be defined when the fate of the highest risks are understood. As analytical and empirical activities are completed to further resolve each identified uncertainty, it is possible that additional discoveries will be made that must be researched and resolved. As these discoveries are made, this working plan will be modified and reviewed.

The risk management system tracks the risks that have been addressed by the work planned and the risks and requirements still needing to be addressed. A risk assessment report, which will be part of the aforementioned Risk Management Plan, will list each risk and show if work has been defined to address it or if that is yet to occur. The risk tracking system that will be used to produce the risk assessment report updates this information in real-time.

EDF-2373 (Barnes, Wood, and O'Brien 2002) has been developed providing baseline process designs for each of the SBW treatment options. Included in the EDF are lists of process assumptions, technical uncertainties, and potential process configuration options. A technical team will review these uncertainties and add or delete from this list, prioritize the uncertainties, define analytical and empirical tests, and execute each in a timely manner. These steps will allow engineering activities to progress based on the selected treatment option, and allow final design to be initiated. 


\subsection{Steam Reforming}

Technical uncertainties, as currently defined for development of the fluidized bed steam reforming option for application to SBW, will be addressed primarily via a series of experiments on surrogate waste at the pilot scale. Two primary steam reforming process/technology options will be tested on surrogate SBW waste and data analyzed to reduce technical process uncertainties and understand the influence of key process parameters. The activity logic and timing necessary to address each issue is presented in Figure 4.

Reformer Chemistry and Operational Mode (H): Chemistry and operating conditions in the steam reformer are not yet adequately defined for the steam reforming process application to SBW. In particular, it has not been determined whether the target product should be predominately carbonates, or whether aluminum and silicon should be added to produce an aluminum ortho-silicate product. The influence of type, ratios, and variations of solid and soluble organic reductant compounds, inorganic additives, fluidizing and feed atomizing gases, bed media, and processing temperature on the steam reforming process chemistry/conditions and resulting products must be sufficiently understood to effectively select and control the process and resulting products. These product and process parameter decisions will affect the design of the steam reforming system, including the fluidized bed, the cyclone and hot-ceramic/metal filter on the reformer off-gas, the locations where solid product will be withdrawn, the likelihood of agglomerate formation in the reformer bed, the need for an inert bed media, the number and type of additive feeders required, the design of effective off gas emissions control, secondary waste products, and the final volume of waste shipped to WIPP. Without sufficient data to provide for quantitative understanding and validation of reformer process chemistry performance and control parameter influence over the range of potential SBW feed applications, there is the risk of needing to redesign and/or replace large subsystems in the treatment process, resulting in significant cost overruns and schedule delays.

Action: The strategy to resolve this issue is to investigate steam reforming performance and controlling parameters influence through testing on surrogate SBW waste in a 6-inch diameter fluidized bed pilot scale test apparatus that has been developed and installed for process and component technology test operations at the Science Applications International Corporation (SAIC) Science and Technology Application Research (STAR) Center. Data are being analyzed and summarized from initial steam reforming process/technology demonstration tests conducted in cooperation with two fluidized bed steam reforming process/technology suppliers in December 2002 (ThermoChem, Inc.) and January 2003 (THOR, Inc.). Evaluation of this data is in progress, but indications are that the process technologies are viable for treatment of SBW. Further testing and supporting analysis will be required to select and optimize the appropriate technology for potential treatment of SBW. Testing is planned to continue in FY 2003 and 2004.

Product Characterization (M): Reformer product characterization data are needed to design the product packaging system and determine the volume of reformer waste. Without these data, there is a risk that the volume of reformer product will exceed the expected volume, increasing disposal costs and affecting shipment schedules. There is also the risk that product transport systems will not meet performance requirements, requiring high-radiation area maintenance or even design and replacement. 
Action: Initial demonstration testing of two steam reforming supplier process/technologies in the 6-inch diameter fluidized bed pilot scale test apparatus has provided simulated product to characterize. Characterization of the product will continue this fiscal year and the first and second quarters of FY 2004 with further testing activities.

Product Densification ( $L)$ : No testing of methods to enhance density of the reformer product has yet been performed. Without these data, there is a risk that the volume of reformer product will exceed the expected volume, increasing disposal costs and affecting shipment schedules.

Action: Vendor testing in the 6-inch diameter fluidized bed pilot scale test apparatus has provided some initial simulated product to characterize. Characterization of this product and engineering evaluations will continue in FY 2003 and 2004, along with further process testing and product characterization activities to determine if product densification may be required.

Off-gas Characterization (H): The off-gas compositions and effectiveness of emissions control technologies and configurations must be better defined through pilot-scale testing. Some specific data needs are (1) flammable gas concentrations and total hydrocarbons (i.e., $\mathrm{H}_{2}$, $\mathrm{CO}$, unburned hydrocarbons), (2) $\mathrm{NO}_{\mathrm{x}}$ concentration, (3) particle loading, composition, and size distribution, (4) volatile radionuclide content, (5) acid gas $\left(\mathrm{HCl}, \mathrm{HF}, \mathrm{H}_{2} \mathrm{~S}, \mathrm{HNO}_{3}\right.$ ) content, and (6) reductant carryover amount. Lacking these data will lead to risks in safety analysis calculations, off-gas system design performance, and insufficient technical bases to support process permitting.

Action: The strategy to resolve this issue is to investigate off gas compositions and effectiveness of emissions control technologies, along with the investigation of steam reforming process performance and controlling parameters influence, through testing on surrogate SBW wastes in a 6-inch diameter fluidized bed pilot scale test apparatus that has been developed and installed for process and component technology test operations at the SAIC STAR Center. Off gas data are being analyzed and summarized from initial steam reforming process/technology demonstration tests conducted in December 2002 (ThermoChem, Inc.) and January 2003 (THOR, Inc.). Evaluation of these data is in progress and initial indications show available off gas emissions control technologies can be selected to support steamreforming treatment of SBW. Further testing and supporting analysis will, however, be required to evaluate, validate, and optimize appropriate off gas system technologies. Testing is planned to continue in FY 2003 and 2004.

Speciation \& Fate of Key Components $(H)$ : Data on the speciation and fate of key components throughout the reformer off-gas system are needed to complete the design of the off gas system to meet emissions requirements. Specifically, data on mercury accumulation in the system is required to determine (1) the characteristics of the secondary salt product, (2) the feasibility of recycling quench solution blow down to the feed, and (3) the expected loading on the GAC beds. In addition to mercury fate and speciation, data are also required for semi-volatile radionuclides such as $\mathrm{Cs}$, Tc, and I. Without these data, there is a risk of producing orphan wastes, or needing to redesign and replace off-gas system components resulting in schedule and cost overruns.

Action: The strategy to resolve this issue is to investigate speciation and fate of key off gas components and control technologies as part of the integrated steam reforming process/system performance and parameter variations testing in the 6-inch diameter fluidized bed pilot scale test apparatus installed at the SAIC STAR Center. Off gas data are being analyzed and summarized from initial steam reforming process/technology demonstration tests conducted in December 2002 (ThermoChem, Inc.) and January 2003 (THOR, Inc.). Evaluation of these data is in progress and indications show available off gas emissions control technologies can be selected to support steamreforming treatment of SBW. Further testing and supporting analysis will, however, be required to adequately characterize the off gas mass/species associated with the steam reforming technology for the 
range of process conditions and evaluate, validate, and optimize appropriate off gas system technologies. Testing is planned to continue in FY 2003 and 2004.

Thermal Oxidizer Kinetics $(M)$ : Reaction kinetics in the current thermal oxidizer design for a SBW steam reforming process may be unfavorable because of the off-gas having a high water content, a low British thermal unit (Btu) content, and a low oxygen content. Thus the present design has a risk that the thermal oxidizer will not meet the required destruction efficiency of $\mathrm{CO}$ and organics, resulting in emissions that do not meet air standards. Design measures could be taken that address each of the identified deficiencies, however, data would still be needed to confirm the feasibility of this operation, and the gas residence time and equipment sizing requirements.

Action: The strategy to resolve this issue is to investigate thermal oxidizer performance and design/configuration variations as part of the steam reformer performance testing in the 6-inch diameter fluidized bed pilot scale test apparatus that has been installed at the SAIC STAR Center. Data are being analyzed and summarized from vendor tests conducted in December 2002 (ThermoChem, Inc.) and January 2003 (THOR, Inc.). Evaluation of this initial data is in progress, but the available data indicate the test apparatus should be modified to include and evaluate a thermal oxidizer as an integral component of the off gas emissions control system. The modifications necessary are being evaluated for installation. Further testing will continue in FY 2003 and 2004.

Off-gas Treatment Configuration (H): The off-gas system design has not been optimized. Many alternate configurations or equipment variations exist to remove solids, quench the reformer and oxidizer off-gas effluents, remove acid gas, and convert $\mathrm{CO}$ and hydrocarbons to $\mathrm{CO}_{2}$ and water. If additional off-gas characterization data were available, optimization could be performed. The risk of not performing these optimizations relates to increase capital and operating costs.

Action: The strategy to resolve this issue is to investigate off gas treatment technology as a part of integrated steam reformer process/technology performance testing using the 6-inch diameter fluidized bed pilot scale test apparatus that has been installed at the SAIC STAR Center. Data are being analyzed and summarized from vendor tests conducted in December 2002 (ThermoChem, Inc.) and January 2003 (THOR, Inc.). Evaluation of these data indicates that the test apparatus should be modified to include and evaluate off gas treatment unit operations more indicative of a production facility. The modifications necessary are being evaluated for installation. Further testing will continue in FY 2003 and 2004.

Results of Initial Steam Reformer Tests: In light of the results of the steam reformer tests performed earlier this fiscal year in cooperation with two steam reforming process/technology vendors, the process team has developed a list of specific issues/questions for further consideration in continued tests and evaluations of steam reforming application to SBW. Many of the issues are similar or closely related to what has been listed above. These include:

- $\quad$ Eliminating excessively high organic or carbon contents of the cyclone product, filter product, and off gas. This will require additional evaluation, test, and optimization of process recipes. Also, consideration of cyclone and hot filter product recycle potential to eliminate excess carbon in solids products. For more effective control of flammable off gas the oxidizer should likely be placed as near as possible to the reformer off-gas outlet. Does it change the method of solids removal? Should the oxidizer be fuel-fired or electric? At what temperature should it operate? Should it be thermal or catalytic? How will it operate under vacuum, i.e., what modifications will be required to standard designs to permit operation under vacuum?

- How can the organic reductant solids best be fed into the bed? Is this a big enough issue to avoid completely by adding all organic to the feed or by using only a liquid organic such as kerosene? 
- If organic materials are added to the feed, what reactions occur and how can they be controlled? If organic solids are used that do not react with the feed, what are the rheological properties of the combined feed?

- Should the scrub be recycled to the reformer, or can we operate without scrub recycle? What is the composition of the scrub? What, if any, species build up in the scrub? How should the final scrub be treated/stabilized for disposal?

- Are there better alternatives to the venturi scrubber that have a lower pressure drop?

- $\quad$ Should the fines from the ceramic filter be recycled to the reformer bed?

- What reformer and feed conditions are needed to avoid a combustible and/or explosive product due to carbon fines?

- How would the reformer be decontaminated, the bed dissolved at turnaround, etc.? Do we want to use an acid decontamination system or some other system?

- $\quad$ How will the process handle a slurry (two phase liquid feed) SBW feed? Could inorganic solid additives be slurry fed and used to tailor the product in the bed and/or cyclone?

Action: Both steam reforming process/technology vendors will be invited to participate in conducting an additional test series to further evaluate and optimize their process for the SBW application. These tests will be conducted in an appropriately modified/improved version of the fluidized bed stream reforming process/technology test bed system at the SAIC STAR Center based on collaboratively developed test plans and a requirements/criteria set supplied by the INEEL. The test schedule is under discussion with the DOE Idaho Operations Office. 
Figure 4. Steam Reformer Flowsheet - Roadmap for SBW Treatment

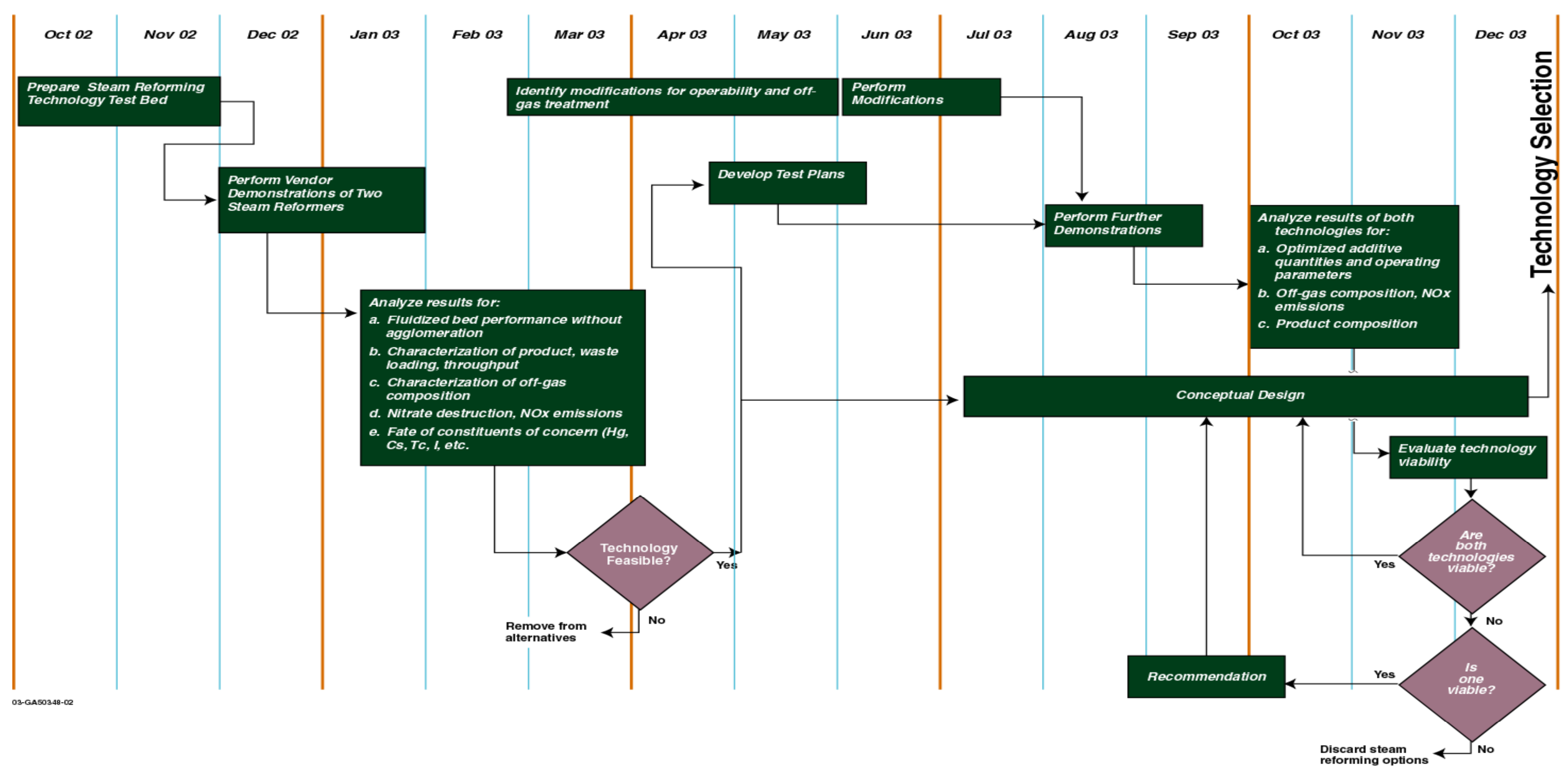





\subsection{Calcination with MACT Upgrade}

The discussion for many of the technical uncertainties presented in this section for the calcination with MACT upgrade option refer to pilot scale testing as an activity for uncertainty resolution. The pilot scale facility targeted for this testing is a modified version of the 6" steam reformer test bed built by Science Applications International Corporation (SAIC) in early FY03 at their Research facility in Idaho Falls, ID. An engineering study (SAIC 2003) identified the required modifications to the steam reformer unit that will allow the facility to be toggled for operation as either a calciner or a steam reformer. Detailed design of these equipment modifications will be available toward the end of FY03 to allow purchase and fabrication of the equipment for installation early in FY04. A calcination pilot test, about two weeks in duration, is planned for December and January FY04. The scope of the pilot scale test has four objectives; 1) validate cyclone efficiency to reduce scrub recycle rates and aluminum nitrate to expected feed composition ratios; 2) assess staged combustion $\mathrm{NO}_{\mathrm{X}}$ destruction efficiency; 3) assess granular activated carbon (GAC) bed performance; and 4) assess a calcination flowsheet that processes SBW after boil down with glycolic acid.

The technical uncertainties itemized below refer to engineering studies and/or a series of experiments for uncertainty resolution. The logic and timing necessary to mitigate each issue are presented in Figure 5.

Minimization of $\mathrm{O}_{2}$ in Calciner Off-Gas $(M)$ : To destroy $\mathrm{NO}_{\mathrm{x}}$ in the MACT Compliance Facility, the initial stage of the staged combustor must operate at reducing conditions. Large quantities of fuel are added to combust the oxygen present in the staged-combustor feed gas. If the oxygen content of this gas, presently expected to be nearly $21 \%$, could be reduced, the fuel to the combustor could be reduced, flow rates through the MACT Compliance Facility would be reduced, and the MACT Compliance Facility footprint would be reduced.

Action: An evaluation of ways to reduce oxygen in the calciner off-gas is recommended. The evaluation could consider partial replacement of kerosene in the calciner with propane, replacement of air for instrument purges with nitrogen, and other methods of minimizing oxygen in the calciner. Demonstration testing of recommendations of this evaluation is envisioned for the pilot scale tests beginning in December 2003. (Calcination, steam reforming, and direct evaporation all have issues with respect to off gas treatment. Where it is practical the common issues will be addressed collectively and resolved to minimize cost and schedule.)

Aluminum Nitrate Ratio/Expected Feed Composition Testing $(H)$ : A reduction in aluminum feed additives used to control calciner bed agglomeration is one of the options under consideration to increase processing throughput to meet a 3-year operation schedule. Pilot plant data are needed for calciner feed with $\mathrm{Al} / \mathrm{Na}+\mathrm{K}$ molar ratios less than the accepted ratio of 2.25. Testing using SBW compositions need to be conducted to verify the applicability of past feed formulations. This is important to validate the SBW feed rate and processing schedule as well as to make sure there are no operating surprises due to present tank chemistry during calcination (O’Brien 2002).

Action: The amount of aluminum nitrate feed additive will be investigated during the pilot scale tests planned to begin in December 2003.

Effects of Zirconium and Phosphate on Bed Agglomeration (H): Determine the effect of the zirconium and phosphate from the solids on bed agglomeration, and determine if additional calcium nitrate is needed in the feed. 
Action: The amount of calcium nitrate feed additive will be investigated during the pilot scale tests planned to begin in December 2003.

Scrub Recycle Minimization Evaluation (H): A reduction in the amount of scrub recycle is one of the options under consideration to increase processing throughput to meet a 3-year operation schedule. Since off-gas scrub recycle makes up $23 \%$ of the feed to the calciner, reducing scrub recycle will allow for an increased SBW feed rate and a reduction of process time.

Action: An engineering study (Bates 2003) determined that replacement of the off-gas cyclone with a new more efficient cyclone could increase the cyclone efficiency from $63 \%$ to about $88 \%$ and result in a SBW processing schedule savings of 166 days. This option to reduce treatment time seems to be viable. However, the major issues relating to the required operating pressure drop for the new cyclone versus available existing blower capacity and personnel exposure estimates for replacing the cyclone remain. These problems need to be examined in more detail before a final recommendation can be made. Action: In order to test cyclone efficiency on calciner operation, a higher efficiency cyclone consistent with the cyclone engineering study mentioned above was designed for inclusion in the calciner pilot facility. The operation of this cyclone will be evaluation as part of the calciner pilot scale testing planned to begin in December 2003.

GAC Bed Chloride Removal- $\mathrm{HCl} / \mathrm{Cl} 2$ Emissions (H): NWCF off-gas samples were taken to measure hydrochloric acid $(\mathrm{HCl})$ and chlorine $\left(\mathrm{Cl}_{2}\right)$ using EPA protocols in 1999 and 2000. All the NWCF off-gas sample results for $\mathrm{HCl} / \mathrm{Cl}_{2}$ were below detection limits, which varied from 9.7 to $55 \mathrm{ppmv}$ total $\mathrm{Cl}$ as $\mathrm{HCl}$ (corrected to 7\% oxygen, dry basis). These bracket the expected MACT standard for new hazardous waste incinerators of $21 \mathrm{ppmv}$ total $\mathrm{Cl}$ as $\mathrm{HCl}$ (corrected to 7\% oxygen, dry basis) (64 FR 189 1999). The off-gas downstream of the noxidizer has been estimated to contain $<7.7 \mathrm{ppmv} \mathrm{Cl}$ as $\mathrm{HCl}$ (Soelberg 2003), which is 2.7 times less than the MACT standard. This only provides a moderate safety factor given variability of chloride concentrations in the feed, potential optimization of air rates to the staged combustor unit and process upsets. An evaluation of options to remove chloride (O'Brien 2003) reviewed chloride sorbents and wet scrubbing operations and recommended removal by the same GAC beds that remove mercury. GAC bed tests in FY 2003 are planned to confirm chloride removal efficiency and chloride loading on GAC.

Action: Using $\mathrm{GAC}$ beds to remove $\mathrm{HCl}$ from the off-gas will mitigate the risk of exceeding MACT chlorine emissions, with replacement of the GAC beds when they become loaded with chlorides. Although present mass balances indicate that the MACT chlorine limit would not be exceeded if the $\mathrm{HCl}$ were not removed, upset conditions and uncertainty in volatile chloride distribution factors result in the potential for exceeding the limit. Based on vender information, $90 \%$ removal by the GAC bed should be achieved, providing a minimum safety factor of five. Preliminary indications of chloride removal by carbon will be available from Long Term tests $(1000 \mathrm{hr}, 1 \mathrm{~cm}$ diameter bed) by August 2003. The test plan is filed as TFP-14-03. Results from breakthrough tests using a larger GAC bed ( $3 \mathrm{~cm}$ diameter) will be available in the $1^{\text {st }}$ quarter FY04 prior to operation of GAC units during calciner pilot tests beginning in December 2003.

Combustor Operating and Performance Parameters (M): The staged combustor operating conditions and expected performance are based on data acquired during testing of a John Zink Noxidizer at Mountain States Energy, Inc. (Butte, Montana) in 1999-2000. These tests used simulated NWCF off-gas and air as the oxidant source for fuel combustion in the reduction chamber and $\mathrm{CO} /$ hydrocarbon oxidation in the reoxidation chamber. One drawback of the Mountain States Energy noxidizer system as configured is its limited ability to reduce the required air and quench rates, which result in a three-fold increase in off-gas rate through the combustor. Researchers have developed kinetic and computational 
fluid dynamics models of the staged combustor (BBWI 2000) that indicate that lower air rates will not compromise NOx conversion.

Action: In order to test lower air and quench rates associated with NOx conversion, a staged combustor was designed for inclusion in the calciner pilot facility. Efforts are planned in early FY04 to develop a Computational Fluid Dynamics (CFD) model of the combustor to be followed later by tuning of the model to results from calciner pilot scale testing planned to begin in December 2003. This modeling is expected to result in recommendations for optimized parameters for staged combustion operation.

GAC Bed Design and Performance (M): For the calcination with MACT upgrade alternative, Soelberg (2003) sized the GAC bed based on four bounding conditions. Those conditions are (1) a vendor recommended gas superficial velocity of $1 \mathrm{ft} / \mathrm{sec}$, (2) the estimated total amount of mercury that will be in the off-gas is $1768 \mathrm{~kg}$, (3) mercury loading of the bed is $11 \mathrm{wt} \%$ based on small-scale test results (Herbst et al. 2002), and (4) assuming sufficient volume in one bed to capture the entire amount of Hg. The bed size based on these parameters would be $16 \mathrm{ft}$ in diameter by $6.3 \mathrm{ft}$ in length. A bed of these dimensions would have a gas residence time of $6.3 \mathrm{sec}$, exceeding the vendor recommended minimum of $2 \mathrm{sec}$, and would also exceed the estimated minimum mass transfer zone length of $2 \mathrm{ft}$. Without additional data confirming these GAC bed performance parameters, the GAC beds could either be oversized, resulting in excessive costs for the beds and for the facility space, or they could be undersized, requiring more frequent bed change-outs. Although GAC bed sizing has not been completed for other treatment alternatives, the same performance parameters are needed to size the beds.

Action: Tests will be conducted to verify the assumptions used in the GAC bed design basis for the removal of mercury from scrubbed calciner off-gas. Results from long-term tests $(1000 \mathrm{hr}, 1 \mathrm{~cm}$ diameter bed) will be available by August 2003 to confirm the $99.9 \%$ mercury removal efficiency assumption of $\mathrm{GAC}$ in the presence of the off-gas constituents $\mathrm{HCl}, \mathrm{SO}_{2}, \mathrm{NO}, \mathrm{NO}_{2}, \mathrm{H}_{2} \mathrm{O}$, and $\mathrm{CO}$. The test plan is filed as TFP-14-03. Results from breakthrough tests using a larger GAC bed (3-cm diameter) will be available in the $1^{\text {st }}$ quarter FY04 to confirm the $11-\mathrm{wt} \%$ mercury bed loading and residence time assumptions and impact of $3 \mathrm{~mm}$ vs. $1.5 \mathrm{~mm}$ particles on performance. GAC performance data will also be produced by the calciner pilot tests that begin in December 2003.

Scrub Treatment Method and Parameters (M): Several tests were initiated in FY03 examining treatment methods for calciner off gas scrub solutions. Scope tests were conducted to evaluate calciner scrub absorption on silica gel, grouting, and absorption on calcine. Scrub can be absorbed on silica gel by first neutralizing it with sodium hydroxide. The resulting mixture contains $55 \mathrm{wt} \% \mathrm{scrub}, 15 \mathrm{wt} \%$ sodium hydroxide, and $30 \mathrm{wt} \%$ silica gel. The mixture is viscous and would require a mixing method (Herbst et al 2003). The scrub can also be grouted as follows: $35 \mathrm{wt} \%$ scrub, $18 \mathrm{wt} \%$ sodium hydroxide, $1 \mathrm{wt} \%$ calcium hydroxide, $41 \mathrm{wt} \%$ blast furnace slag, and $5 \mathrm{wt} \%$ Portland cement (Herbst et al 2003). A single component grout was not found to date nor is one expected to be found due to the high acid and nitrate content of the scrub solution. Absorption of scrub on calcine is possible if the process loading is less than $10 \mathrm{wt} \%$ (Scholes et al 2003). Higher loadings generate gases and heat. Each of the above processes should meet the WIPP acceptance criteria. Questions that have yet to be researched are: a) At these loadings, does hydrogen generation due to radiolysis present a problem, b) Can the waste be added to sorbents "in-can" or what mixer is needed, c) What are the transport and physical properties of the absorbed waste and the absorption rate (Haefner, 2003)?

Action: Engineering trade-off studies are needed in FY04 to evaluate process feasibility and costs to select one of the above processes. This also applies for the steam reformer and direct evaporation alternatives; in FY04 experiments addressing secondary waste immobilization are planned for all three 
technologies. It is expected that scrub from the steam reformer alternative will be very similar in composition to that from calcination with the exception that the solution will not be transuranic; thus it will not go to WIPP, but to Hanford or the Nevada Test Site. Therefore, TCLP tests will be conducted for mercury in the steam reformer scrub waste form to verify that it will meet the land disposal requirements of these sites.

Off-gas Cl concentration and speciation (M): The current best calciner off-gas chloride concentrations are all based on less-than detection values from calciner off-gas sampling. A quantifiable concentration of $\mathrm{HCl} / \mathrm{Cl}_{2}$ in the calciner off-gas is needed for accurate bed sizing for chloride removal, or else the beds volume may be unnecessarily oversized. The speciation of $\mathrm{Cl}$ in the off-gas downstream of the noxidizer is also needed for the chloride removal system design (O'Brien 2003).

Action: Calcination pilot tests planned to begin in December 2003 will provide data regarding $\mathrm{Cl}$ concentration and speciation downstream of the calciner.

Mercury Vapor Liquid Equilibrium Data (M): Past attempts to determine mass balances for mercury in NWCF runs have resulted in more mercury in the feed than could be found in the products. The difference in the mass balance mercury, even if only a few percent of that in the feed, could have a large impact on the off-gas mercury concentration and the amount and timing of scrub purge during the SBW processing campaigns. Additional mercury (all $\mathrm{Hg}$ species in calciner off-gas) vapor liquid equilibrium data using calciner off-gas and scrub simulants is needed to better determine the amount of scrub waste and design an adequate treatment system. Another question relative to $\mathrm{Hg}$ vapor liquid equilibrium data is "to what concentration can mercury build up before precipitation?" Present scrub data show $\mathrm{Hg}$ as high as $60 \mathrm{~g} /$ liter, but we have no experience at higher concentrations.

Action: A thermodynamic model development effort began in FY03 to support off-gas mercury design issues. The end of fiscal year 2003 should complete specialized regression routine customization to allow for regression of model parameters from equilibria data in FY04. Sources of mercury vaporliquid equilibrium data for this purpose will be pursued including results from FY03 testing that was performed in support of the direct evaporation alternative.

Feed Acidity $(L)$ : The current SBW and projected NGLW have a higher acidity than previous SBW blends, causing concern for increased likelihood of bed agglomeration (Olson, 2002). Testing is necessary to substantiate the validity of these concerns and identify if modifications in feed additives to accommodate higher feed acidity are needed.

Action: Evaluation of the impact of higher feed acidity on calciner operation will be accomplished as part of pilot scale tests that begin in December 2003.

Effect of Solids on Calcination (M): Pilot runs are needed to confirm the effects of tank solids on feed blend parameters and calciner operation with expected level and composition of solids. Solids characterization and simulant development activities in FY03 will provide guidance for incorporation of solid simulant in calciner pilot testing.

Action: Solid simulant will be included as part of the feed in calciner pilot plant testing that begins in December 2003.

Calcine Densification ( $L$ ): Verification of the assumed calcine density is needed to avoid the risk that the volume of calcine will exceed the expected volume, increasing disposal costs and affecting shipment schedule. 
Action: Although, this is a considered a low risk, calcine densities can be measured for product obtained during calciner pilot plant tests that will begin in December 2003. 
Figure 5. Calcination/MACT Upgrade Flowsheet - Roadmap for SBW Treatment

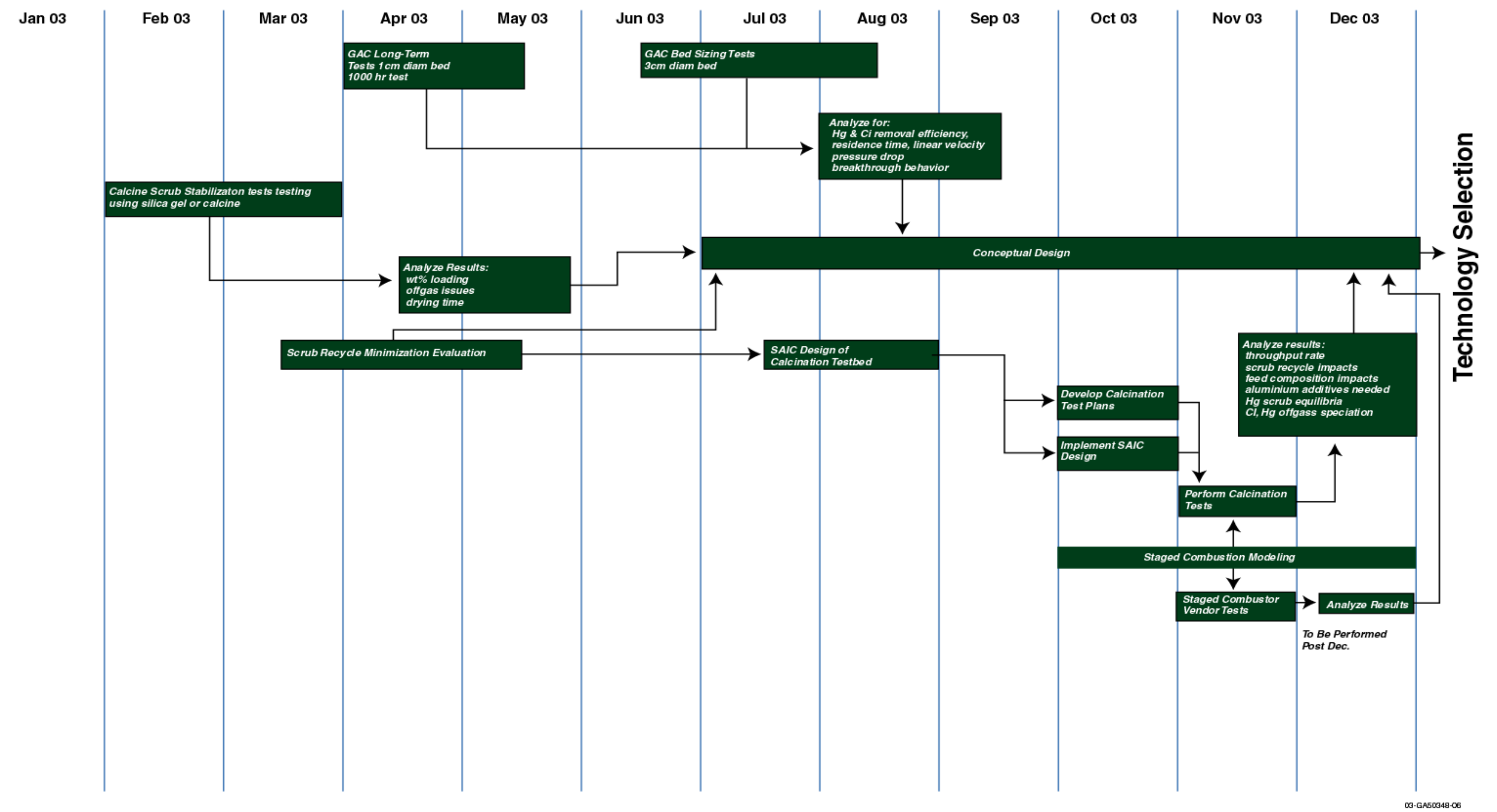





\subsection{Cesium Ion Exchange with Immobilization}

The technical uncertainties as defined for development of the CsIX with immobilization option will be addressed via a series of experiments at the laboratory and pilot scale. The logic/timing decision flow sheets (Figures 6 and 7) identify the roadmap necessary to mitigate the following issues:

Solid/Liquid Separation Technology $(H)$ : Solid/liquid separation is required in the CsIX/TRU grout process to remove undissolved solids from SBW prior to the CsIX column. Both undissolved solids and tank solids are not well characterized; thus, there is risk that the design of the column filter may not meet performance requirements. Adverse effects, such as, frequent filter plugging may lead to process inefficiencies and prolonged downtime. Relative to undissolved solids filtration, the risk is creating a SBW grout that would be remote handled rather than contact handled since the unfiltered solids would be highly radioactive and possibly pass through the column.

Action: A solid/liquid separation technology prior to the CsIX column will be tested. A cross flow filtration technique will be validated using a small-scale test system and a SBW surrogate containing simulated solids at the low concentrations existing in the acidic SBW waste tank. The cross flow tests have been designed to evaluate a number of variables parametrically providing data to optimize the system in terms of filtrate clarity, throughput, and minimal plugging. Key parameters to be studied include type of solids, concentration of solids, pressure, flux, final permeate concentration, and filter pore size.

Past experience with cross flow filtration has shown superior performance in removing solids down below 1 micron in size. In addition, cross flow filtration, as opposed to cake filtration, should have a lower risk in regard to filter plugging, since cross flow filtration will continually sweep the filter surface as the clean effluent is radially discharged toward the ion exchange column. As a result, the unfiltered solids will concentrate in a portion of the recycled tank waste and be subsequently discharged to a solid's decant tank when the solids level reaches $\sim 20 \%$. Simulated solids accuracy will be approached through tank farm sampling coupled with lab activities to determine the chemical and physical structure of the actual solids so they can be replicated with the use of advance analysis methods as well as contracted modeling methods. A range of expected solid's types, size distribution, and concentrations will be tested to ensure that the cross flow filters can handle conditions out side the expected norm. Several different filter media with a range of pore sizes will also be tested. Under these conditions, there is little doubt that the cross flows will provide sufficient filtering to ensure ion exchange column performance in regard to Cs removal. Even though available Tank solids particulate size distribution (PSD) data show undetectable and very minute amounts below 0.5 micron, there is a concern that such solids may plug, or in the worst case, pass through the ion exchange column. If such a remote phenomena should occur, the grouted effluent may lose its radiolytic contact status if the minute particles are extremely radioactive. Testing is planned to determine the effects of these relatively large amounts of minute solids if detection/methods for such a low PSD are formulated.

Solids Processing and Disposal $(H)$ : The present flow sheet assumes that the solids from the cross flow permeate, as well as, from tank sluicing and flushing can be consistently filtered, dried, and packaged as a dried solid in canisters for WIPP disposal. If either the filtration or drying step cannot be demonstrated, an alternative treatment system would be required. If the solids cannot be dried to the moisture content required for disposal, an alternative or supplemental drying system would need to be used. In addition, the solids must be processed in a consistent manner to ensure $100 \%$ compliance to transportation as well as WIPP disposal criteria. If development indicates that such a lofty goal cannot be met, the CsIX flow sheet loses significant validity. 
Action: Several levels of testing will occur over FY 2003 with the primary objective of validating a Fundabac brand arrangement of cartridge filters as an acceptable method of ensuring a dried, removable, fluid, and acceptable remote waste cake product that is within the defined specifications for compliant transfer to and disposal at the WIPP site. Experiments will begin with small-scale hot (using actual tank waste solids concentrated up to 30\%) and cold filter testing to define the fundamental range of acceptable filtering and drying parameters. The tests will identify key solid filtering properties, such as, cake resistance and compressibility, properties that will need to be duplicated by the identified solid's surrogate. The small-scale tests will also determine the proof-of-principle for air-drying after filtration under constant pressure conditions. Tank waste solutions containing solids will be simulated for the cold tests and simulation/surrogate recipes will be prepared via an extensive tank characterization effort coupled with a surrogate preparation study involving both detailed chemical and physical analysis. Hot and cold test results will be continually compared and surrogates routinely altered until test results become similar. Once a reliable surrogate is established, small-scale cold test under constant flow pressure with an actual Fundabac system will be conducted to optimize operating parameters to best achieve dry solid product specs as defined for compliant transfer to and disposal to WIPP. Such tests will provide critical data to process engineering and conceptual design and will be conducted under a variety of alternating parameters involving throughput, duration until blowback, type and concentration of solids, cake thickness, and length and type of drying. Test plans for the small-scale Fundabac test will be developed in part with assistant of a consultant with expertise in cake filtration and drying. Success at the small scale Fundabac test level will, in part, justify the CsIX flow sheet for continued design and development. Follow on testing with the most advanced and accurate cold surrogate and a larger or full scale Fundabac will then be initiated to directly support design efforts.

Sorbent Performance/Selection and Disposal $(H)$ : The CsIX/TRU grout process requires removal of sufficient cesium $(99.9 \%)$ so that the resultant waste, when grouted, can be disposed as contact-handled waste. Testing in FY03 (Tranter 2003) provided data on sorbent stability, sorbent TRU retention, sorbent equilibrium isotherms and small-scale dynamic column tests for the sorbents crystalline silico-titanate (CST) and ammonium molybdophosphate impregnated silicaalumina cenospheres (AMP-C). CST is recommended as the baseline sorbent. Equilibrium and dynamic testing with each of the sorbents demonstrated them to have adequate selectivity and capacity for removing cesium from the complex acidic waste matrix. Furthermore, it was shown that AMP-C maintains acceptable stability in the waste simulant, but to improve the stability of the CST during continuous column operation, it was necessary to reduce the acidity of the feed to approximately $0.5 \underline{\mathrm{M} \mathrm{HNO}_{3}}$. The dynamic CST stability data appears inconsistent with static test data generated in late FY02 (zirconium dissolution of $0.5 \%$ in 8 weeks for static tests versus 15.2 to $18.5 \%$ dissolution in less than a week for dynamic tests) and will require additional investigation to resolve.

The sorbent TRU retention test established that there is sufficient TRU in the liquid held up in the pores of the sorbent that the spent column will be considered TRU waste for disposal at WIPP. However, quantification of the additional TRU retained on the sorbent through adsorption is still necessary to verify that there is no spent sorbent criticality issue.

Action: Dynamic tests with both sorbents are planned for completion by August 2003 to confirm the small-scale test results with simulant at a semi-test scale ( $500 \mathrm{ml}$ column) adequate to confidently predict full-scale performance. Follow-on tests in FY 2004 with actual waste are recommended at the appropriate scale based on evaluation of the small-scale and semi-scale results. In addition, resolution of CST stability in the acidic SBW feed and sorbent capacity for TRU to address its criticality potential will be investigated. 
Grout Formulation (L): The primary data need relative to grouting is (a) long-term stability of grout using the proposed formulation, including volatile organic compound release, water release, and drum corrosion (b) the effect of freeze/thaw cycles on grout stability, (c) optimization of the grout formulation, (d) cooling requirements for neutralization, and (e) grout cycle times. Risks stemming from not obtaining these data include the risk of producing grout not meeting waste acceptance criteria, a grout formulation that is not optimized would result in higher capital or operating costs, and the potential need for redesign of the neutralization cooling system.

Action: Grout formulation testing is planned throughout the remainder of FY 2003 addressing items (b) and (c). Item (d) will be addressed through a subcontract (perhaps with Idaho State University). The decision to further pursue item (a) has been deferred until after selection of an SBW treatment alternative.

Silica Gel (L): Absorption of the ion exchange effluent on silica gel, with or without subsequent evaporation, represents alternatives to grouting. However, for process simplicity, direct absorption without heating was studied in FY03 (Herbst et al 2003). At $70 \mathrm{wt} \%$ loading (70 wt $\% \mathrm{SBW}$ and $30 \mathrm{wt} \%$ silica gel) the waste form meets the WIPP requirements of no free liquid. Initially, the SBW was applied to the silica gel during a rotary mixing/drying kiln process; however, later scope tests showed that the silica gel could be added to the SBW without mixing. In this case, the silica gel is sprinkled on the surface of the liquid, where it absorbs the liquid, and settles to the bottom. One finding of concern was the acidic vapor coming off the post-treated silica gel. When litmus paper was placed in the headspace of the sample bottle, it readily turned red in a matter of seconds. For samples, that were pre-neutralized to a $\mathrm{pH}$ over 2, the acidic vapors were reduced. In this latter case, it took several hours for the litmus paper to turn red.

Action: Evaluation of the flowsheet implications of these immobilization results as an alternative to grouting will determine the need/scope of follow-on testing.

Grout Mixing (L): Data are needed on in-drum and out-of-drum mixing in order to optimize the grout mixing method. The decision to mix in-drum versus out-of-drum has implications for the amount of waste produced, the processing rate and hence the number of grouting lines required, and auxiliary system design. The risk of not obtaining this data is primarily the incremental costs of a grouting system that is not optimized.

Action: Out-of-drum mixer tests are scheduled through the remainder of FY 2003. The decision to pursue an in-drum mixing subcontract with the Atomic Energy Authority of the United Kingdom has been deferred until after selection of an SBW treatment alternative. 
Figure 6. Cesium Ion Exchange with Immobilization - Roadmap for SBW

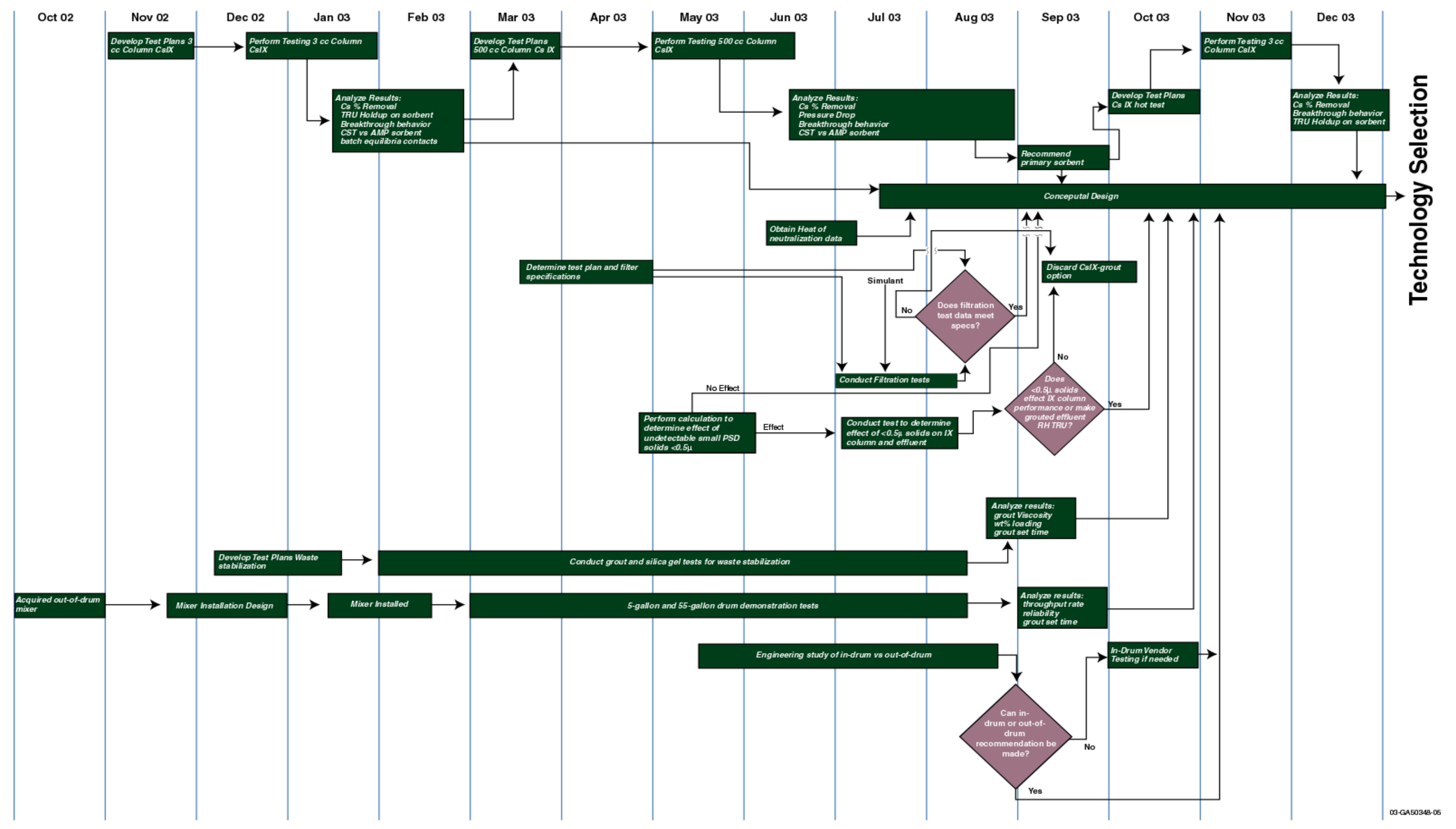



Figure 7. Characterization and Solids Treatment

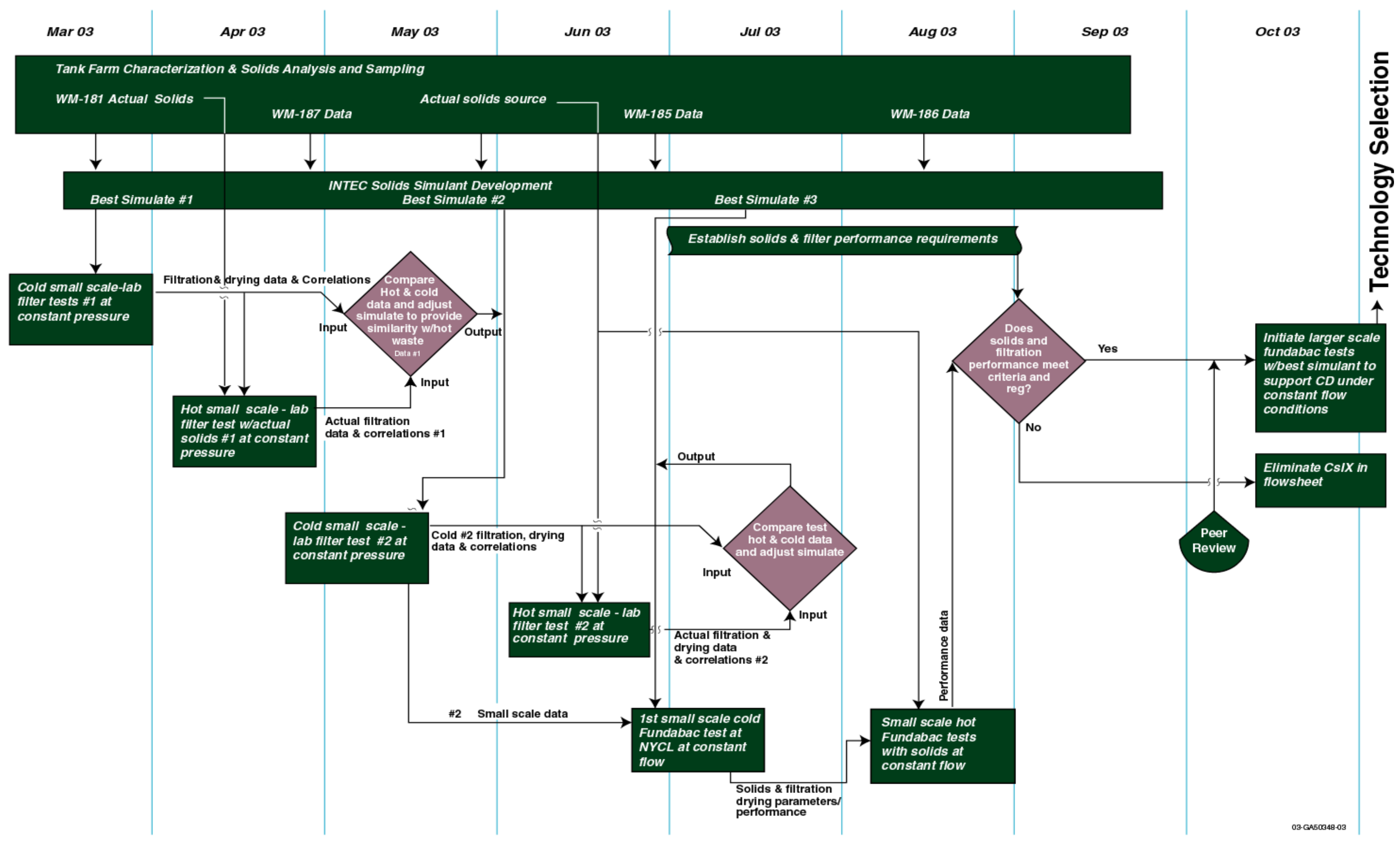





\subsection{Direct Evaporation}

The technical uncertainties as defined for development of the direct evaporation option will be addressed via a series of experiments at the laboratory and pilot scale. The logic and timing necessary to mitigate each issue is presented in Figure 8. Additionally each uncertainty has been evaluated against an established consequence and probability criteria, resulting in its classification in one of three categories: high, moderate, and low. The extent and the depth of the development activities, as indicated in Figure 8, have been established based on this assessment.

Liquids and Heel Solids Co-processing (M): The present direct evaporation flow sheet shows separate processing of SBW and heel solids. However, if the heel flush solution were initially dewatered by decanting in the heel-receiving tank, the heel slurry could be blended with the SBW and co processed in the evaporator. Based on high-level liquid waste evaporator operation on high solids SBW feed blends, much of the solids will dissolve during the evaporation step, so they will not cause problems in the evaporator and may actually enhance the solidification upon cooling. Co-processing may also be necessary if the heel solids filter cake has poor permeability making it difficult to filter, as was indicated by analytical lab tests on WM-180 undissolved solids. However, a plan for the processing of the last heel solids from the tanks would need to be identified. It is likely that these last heel solids could be blended with cold chemicals (sodium and aluminum nitrate) to produce a composition similar to SBW, and then evaporated and directly solidified.

Action: The co-processing of solids with liquids during evaporation is critical if the evaporator option is to be fully successful as planned. Therefore, this risk has been classified as moderate. Past history with evaporators at INTEC have established that acceptable evaporation is possible as long as little or no solids exist in the waste to be evaporated. However solids can hinder traditional evaporation via fouling and subsequent degradation in heat transfer coefficients, and therefore special evaporators, such as wiped film evaporators will be studied after liter glass scale tests and in-can tests are completed to define operating parameters. These tests will specifically determine if the adverse effects of solids can be mitigated with the use of a different type of evaporation system and still produce a consistent WIPP transportation and disposal compliant bottoms product solid. In addition, modifications to traditional evaporation systems, such as kettle and thermal siphon evaporators, will also be investigated. Along with development work on the evaporation side, additional studies will be performed to identify optimum techniques for mixing and feeding the solids in and from the tanks.

Product Characterization (H): Product characterization data are needed for the solidified SBW waste over the full range of evaporator feed composition. Obtaining these data will provide a basis for defining the required envelope of operating conditions for the evaporator and reduce the risk of producing a waste product that would not meet waste acceptance criteria for either transportation or disposal at WIPP. It is paramount that a consistent bottoms product can be produced and that this consistency can be maintained through the control of certain evaporation operating parameters as defined through the development described below. The inability, during development, to ensure both transportation and WIPP disposal complaint product consistency may lead to elimination of the direct evaporation as an option.

Action: Mitigation of this uncertainty will take place via testing and associated sampling and analysis. Specific tests that will generate bottoms product for a first screening assessment of the product qualities and characteristics include the following SBW surrogate experiments: One liter glass flask scale tests, 5-gallon in-can evaporator tests, and a $1.4 \mathrm{ft}^{2}$ scale test run with a wiped film evaporator will be completed with all tests being continuous. All of these tests will generate surrogate samples for testing. These samples will be analyzed for free liquids as well as any oxidation hazard via the standardized Department of Transportation test. General solids behavior will also be qualified through experimental 
observations of pouring qualities, long and short-term durability, degassing, and corrosion potential. A critical part of this development effort will be to define the controllable evaporator parameters that can consistently maintain the bottoms product in the prescribed specifications.

Equipment Type (M): Several alternative evaporator types could be used in this process. Evaporation has typically been performed in thermosyphon evaporators (high-level liquid waste evaporator and process equipment waste evaporator) at INTEC, although the high boil down for direct evaporation will likely cause some precipitate formation in the evaporator that could foul the reboiler tubes. Thin film type evaporators have been used successfully for evaporation of chemical weapons waste, but there are concerns about maintenance of the wiper blades and motor in a highly radioactive system. Evaporation directly in the waste canisters would reduce the number of unit operations however, process control would be more difficult, and the heat transfer area would limit the processing rate such that multiple canister processing trains would be required. Evaporator demonstration tests are needed first to verify performance, establish design parameters, and reduce the risk of operational problems.

Demonstration tests of different types would allow optimization of the evaporator.

Action: The equipment risk issue will be resolved by evaluating various evaporator types and/or evaporator type-combinations as related to the materials-fouling as well as solid issues. Evaporators will be tested under simulant, and possibly under later actual conditions. Included for testing are in-can systems, thin and wiped thin systems and thermosyphon systems. Each test involving each piece of equipment will obtain data relevant to assessing the fouling/corrosion and overall reliability, operability, and maintainability of each type, as well as their ability to handle the above-normal level of solids. Since a wide range of evaporator types and combinations will be evaluated, there is a high likelihood that one or more options will show success. As such, this risk has been assessed as moderate. Data will also be obtained from other operating evaporation systems treating applicable waste with in the DOE system. Representatives from Bechtel BWXT Idaho, LLC and DOE Idaho Operations Field Office have met with personnel at Oak Ridge and have reviewed their evaporation system with a report to follow this fiscal year.

Materials Evaluation ( $L)$ : The high acid and chloride concentrations in the evaporator bottoms will be quite corrosive. Materials corrosion testing are needed using simulated evaporator bottoms to identify a material that will have acceptable corrosion during the life of the SBW treatment facility. Even though this risk has been defined as low, not performing these tests carries the risk of material failure during operation.

Action: Corrosion, scaling, salting and overall equipment wear issues will be mitigated through a series of small, pilot and prototype testing as deemed necessary. Early tests involving laboratory scale glass evaporators, in-can evaporators, and contracted pilot scale wiped film evaporators will provide fundamental mass balance data needed to quantify the extent of corrosive species, their form, and their place of accumulation. Such species include, but may not be limited to chlorides, fluorides, acids, and solids. Once the type of corrosive species are identified further tests involving pilot and prototype evaporators with various off-gas/condensate treatment trains will be utilized to determine parameters needed to operate the evaporators and corresponding selected downstream processing equipment in a manner to minimize corrosion. Test coupons will also provide insight into material selection and collectively all of this test data should be able to assist an Architectural Engineer in selecting and designing an evaporator system sufficiently resistant to corrosion-especially in light of its relatively short operating life.

Condensate Treatment $(L)$ : Several alternatives exist for condensate treatment that may be considerably cheaper than concentrating the condensate in the process equipment waste evaporator/LET\&D and grouting the resulting acid. Other options are to add a mercury removal bed and 
then treat the nitric acid evaporator vapor directly with an $\mathrm{SCR} \mathrm{NO}$ abatement system or as condensate in a biodenitrification reactor. This would eliminate the condenser, grout system, and the acid grout waste stream. Demonstration tests are needed first to confirm that grouting LET\&D bottoms results in a disposal waste. Even though this risk has been defined as low, testing of alternative treatment systems would provide a basis to select the optimal system.

Action: To mitigate the risk associated with the direct evaporation option off-gas and condensate issue, it will be necessary, at the onset, to determine the off-gas/condensate composition through a mass-balance. This information will be generated through a series of ongoing laboratory, bench and pilot scale studies involving in-can, wiped film and thermosyphon evaporators. Once these compositions are determined, developers will be able to define and test various off-gas/condensate treatment strategies. Data from the mass balance and the conceptual design of the proposed off-gas condensate treatment system will provide the necessary information to select and design an evaporation off-gas treatment train that is acceptable in terms of cost and grout volume, as well as compatible with existing INTEC systems such as the process equipment waste evaporator and LET\&D. 
Figure 8. Direct Evaporation Flowsheet - Roadmap for SBW Treatment







\subsection{Uncertainties Common to Calcination, Steam Reforming, and Direct Evaporation (Wood and Morrell 2002)}

Tank Solids Characterization (H): Tank sampling is needed to better determine the quantity, transport properties, and composition of tank solids (Barnes and Millet 2003).

Action: This need has been addressed in PLN-1129, the Tank Sampling and Characterization Plan; sampling of tanks for solids will be done in FY-03 and subsequent years.

Mixing Pump Selection and Modeling (L): As part of the conceptual design or separate studies, (a) an optimal pump design should be selected, (b) the interface and impacts of using pumps on tank closure should be clarified (c) computational fluid dynamics models should be constructed and used to understand mixing behavior, and (d) the impact of pump nozzles on tank erosion should be studied.

Action: An engineering study to select and test mixing pumps has been completed and is under review. The initial recommendation from the study is to use submersible rather than long-shafted pumps. Submersible pumps will need to be qualified for the application.

Mixing Pump Performance Demonstration (L): Tests should be performed to validate the effectiveness of the mixing pump design and the placement within each tank.

Action: An engineering study is currently under way to identify test objectives and to evaluate potential locations for performing the tests.

\subsection{SBW Treatment Options-Material Handling Considerations}

Potential design, development, and implementation risks exist with respect to product waste handling for all four identified alternatives. The behavior of compounds exiting each treatment system, product, and secondary waste, must be well understood from a material-handling perspective. The end products of both calcination and steam reforming are a powder. Powder handling is a highly specialized area of chemical engineering requiring a thorough review of the material handling needs. The end product of the direct evaporation alternative is a molten salt requiring a clear understanding of the correct handling temperatures, physical and rheological properties. For CsIX with an immobilization step, the end products are the ion exchange sorbent and ion exchange effluent that is to be immobilized. The spent ion exchange sorbent must be treated and packaged as a remote-handled waste leading to additional material-handling risks. The ion exchange effluent will involve several material-handling steps to immobilize and package the resulting product.

The technical objectives of the material-handling system review for each alternative are:

- Demonstrate that dry solids handling systems provide a smooth flow of material

- Demonstrate the ability to maintain containment and transport final product from treatment system to transportation container

- $\quad$ Provide data for equipment design, regulatory permits, and SBW treatment facility operation

- Demonstrate the handling of remote-handled ion exchange sorbents

- Validate the design basis for the design of the material-handling unit operation for each treatment alternative. 
As the test plans are generated and reviewed for each treatment alternative, material-handling will be a key high-level requirement. The scope of each test will include generating data for the design of material-handling systems for each alternative. Testing will be at a sufficient scale to predict and ensure equipment performance and system reliability at full scale. 


\section{APPLIED TECHNOLOGY PLAN SCHEDULE AND FUNDING}

The intent of the technology development activities of the SBW Treatment Facility program is to perform the necessary technology development and testing required, providing data supporting the recommendation of one treatment technology from four identified alternatives. The time frame for the selection by the DOE Idaho Operations Office was January 2004, with the final recommendation provided to DOE Headquarters also during January 2004. Roadmaps shown in Section 4 were developed to provide the data required to achieve this objective.

The following table summarizes the activities that are to be performed in fiscal year 2003 and the approved funding level for each of the activities.

\begin{tabular}{|c|c|c|}
\hline ACTIVITY & DESCRIPTION & $\begin{array}{c}\text { FY03 \$ } \\
\text { (BASELINE) }\end{array}$ \\
\hline Applied Technology & & \\
\hline Thermodynamic Modeling & $\begin{array}{l}\text { Formulate and execute a computerized procedure to } \\
\text { estimate (regress) requisite physical properties for } \\
\text { thermodynamic calculations. Generate a database of } \\
\text { Pitzer parameters for constituents of the INEEL's } \\
\text { present/future process streams. This database will be } \\
\text { imported into ASPEN-Plus to do process modeling } \\
\text { using the Pitzer model. The focus of this process } \\
\text { modeling will be to provide mechanistic predictions of } \\
\text { the fate of species of concern. Provide ability to predict } \\
\text { chemical speciation and partitioning between gas, } \\
\text { liquid, and solid phases. }\end{array}$ & $\$ 272 \mathrm{~K}$ \\
\hline $\begin{array}{l}\text { Characterization/Simulant } \\
\text { Development }\end{array}$ & $\begin{array}{l}\text { Sample TFF (liquid and heel solids), perform analytical } \\
\text { analysis (physical, chemical, radiochemical), write } \\
\text { reports, and develop simulants representative of liquid } \\
\text { and heel solids for experimental process development } \\
\text { activities and eventual facility design. }\end{array}$ & $\$ 1,097 \mathrm{~K}$ \\
\hline CMACT & $\begin{array}{l}\text { Perform long-term exposure and breakthrough } \\
\text { experiments with Granular Activated Carbon (GAC) } \\
\text { beds to assess Hg removal performance. Perform } \\
\text { experiments with glycolic acid boil down of SBW to } \\
\text { reduce volume requiring processing. }\end{array}$ & $\$ 636 \mathrm{~K}$ \\
\hline Steam Reforming & $\begin{array}{l}\text { Perform demonstrations of individual vendor } \\
\text { technologies within test bed located at SAIC STAR } \\
\text { Center. Includes modification of the test bed to enhance } \\
\text { vendor technologies and optimizing process chemistry. }\end{array}$ & $\$ 3,984 \mathrm{~K}$ \\
\hline
\end{tabular}




\begin{tabular}{||l|l|l||}
\hline CsIX Sorbent Performance & $\begin{array}{l}\text { Perform batch equilibrium and dynamic small-scale } \\
\text { column experiments to assess sorbent performance and } \\
\text { stability. Perform larger scale fixed-bed (500 cc) } \\
\text { experiments to understand sorbent behavior. }\end{array}$ & $\$ 432 \mathrm{~K}$ \\
\hline Solids Filtration/Drying & $\begin{array}{l}\text { Perform experiments to verify that solids can be } \\
\text { removed from SBW feed to a fixed-bed Cs removal } \\
\text { system, perform experiments to verify that bulk heel } \\
\text { solids can be collected, dried, and packaged for disposal } \\
\text { at WIPP. }\end{array}$ & $\$ 929 \mathrm{~K}$ \\
\hline Immobilization (Grout/Silica & $\begin{array}{l}\text { Perform waste formulation and out-of-container mixing } \\
\text { experiments to validate that acceptable waste forms can } \\
\text { be generated for disposal at WIPP or a mixed, low-level } \\
\text { waste disposal site. }\end{array}$ & $\$ 845 \mathrm{~K}$ \\
\hline Direct Evaporation & $\begin{array}{l}\text { Perform tests to determine acceptable evaporation } \\
\text { concentration levels, constituent mass balances, product } \\
\text { properties, and equipment types that will produce } \\
\text { acceptable products and be reliable in a radioactive } \\
\text { environment. }\end{array}$ & $\$ 1,120 \mathrm{~K}$ \\
\hline Process Engineering & $\begin{array}{l}\text { Preparation of process flow diagrams (potential process } \\
\text { configurations), mass balances, process descriptions, } \\
\text { process basis, equipment list, identification of technical } \\
\text { (Feed Composition for the Sodium-Bearing Waste } \\
\text { Treatment Process) based on characterization data. } \\
\text { Initiate Waste Analysis Plan and support Hazards } \\
\text { Analysis and Environmental Permitting. }\end{array}$ & $\$ 1,303 \mathrm{~K}$ \\
\hline \hline
\end{tabular}

During the third quarter of this fiscal year DOE announced that the treatment of the sodium-bearing waste would be included at part of the Idaho Completion Project re-bid proposal. With this announcement Bechtel BWXT Idaho, LLC is in the process of discussing with DOE their requirements for the remaining portion of the alternative selection process. The product of this discussion will be an identified set of project activities, required funding, and a new schedule. 


\section{REFERENCES}

Barnes, C. M., and C. B. Millet, Feed Composition for the Sodium-Bearing Waste Treatment Process, INEEL/EXT-2000-01378 Revision 2, January 2003.

Barnes, C. M., R. A. Wood, and B. H. O'Brien, "Process Design of SBW Treatment Alternatives," Engineering Design File EDF-2373, September 10, 2002.

Bates, S. O. and M. G. McKellar, "NWCF Cyclone Replacement Options for Calcination with MACT Upgrade SBW Treatment Alternative", Engineering Design File EDF-3646, May 8, 2003.

BBWI Internal Report: Modeling of a Multi-Stage Combustor (Noxidizer) for Treatment of NWCF Off-Gas, INEEL/INT-2000-01317 Rev. 0, September 2000.

Haefner, D. R., "Scrub Treatment Options Evaluation for the Calcination with MACT Upgrade SBW Treatment Alternative," Engineering Design File EDF-3325 Rev. 0, March 4, 2003.

Harmon, H., M. Duffy, W. Schulz, L. Tavlarides, and M. Thompson, "Independent Review Committee Report—Sodium-Bearing Waste Treatment Facility Identified Treatment Options", February 4-6, 2003.

Herbst, A. K., J. A. DelDebbio, R. J. Kirkham, B. A. Scholes, and T. L. Watson, Idaho Nuclear technology and Engineering Center Sodium-Bearing Waste Treatment Research and Development, INEEL/EXT-02-00985, Rev. 0, September 2002.

Herbst, A. K., S. V. Raman, S. H. Hinckley, and R. D. Colby, "Preliminary Results for Solidification of Simulated Liquid Effluents from Sodium-Bearing Waste Treatment Options", Engineering Design File EDF-3788, May 15, 2003.

Murphy, J. M., W. B. Palmer, and K. J. Perry, Sodium Bearing Waste Processing Alternatives Analysis, INEEL/EXT-2000-00361, May 2000.

Murphy, J., et al., Assessment of the SBW Treatment and Disposition Alternatives Decoupled from Calcine Treatment, INEEL/EXT-02-00265, February 2002.

O'Brien, B. H., "Calciner Throughput Evaluation for Calcination with MACT Upgrade SBW Treatment Alternative,” Engineering Design File EDF-3212 Rev. 0, December 5, 2002.

O'Brien, B. H., "Off-Gas Chloride Control for the Calciner MACT Compliance Facility," Engineering Design File EDF-2205 Rev. 0, April 3, 2003

Olson, A. L., E-mail from B. O’Brien to A. Olson on December 17, 2002.

Olson, A. L., Process Technology Development (Informal Notes), March 2003.

Perry, K. J., Sodium-Bearing Waste Treatment Facility Project Alternatives Analysis Process and Results, INEEL/EXT-02-00994, September 2002.

SAIC, “SR/Calcination Modifications Feasibility Study” February 28, 2003. 
Scholes. B. A. and S. H. Hinckley, "Absorption of NWCF Scrub Solution onto Calcine", Engineering Design File EDF-3794, May 19, 2003Soelberg, N. R., "Off-Gas Mercury Control for the Idaho Tank Project—Calcination with MACT Upgrade SBW Treatment Alternative," Engineering Design File EDF-3292 Rev. 0, February 28, 2003.

Tranter, T. J., "Evaluation of IONSIV IE911 and AMP-Cenosphere Composites as Cesium Removal Options for INEEL Acidic Tank Waste”, Engineering Design File EDF-3602, May 23, 2003

Wood, R. A., and D. K. Morrell, "Heel Solids Processing Evaluation for the SBW Treatment Project Calcination with MACT Upgrade Alternative," Engineering Design File EDF-3049 Rev. 0, December 4, 2002. 


\section{Appendix}

SBW Treatment Alternatives - Process Flow Diagrams 
Steam Reforming 


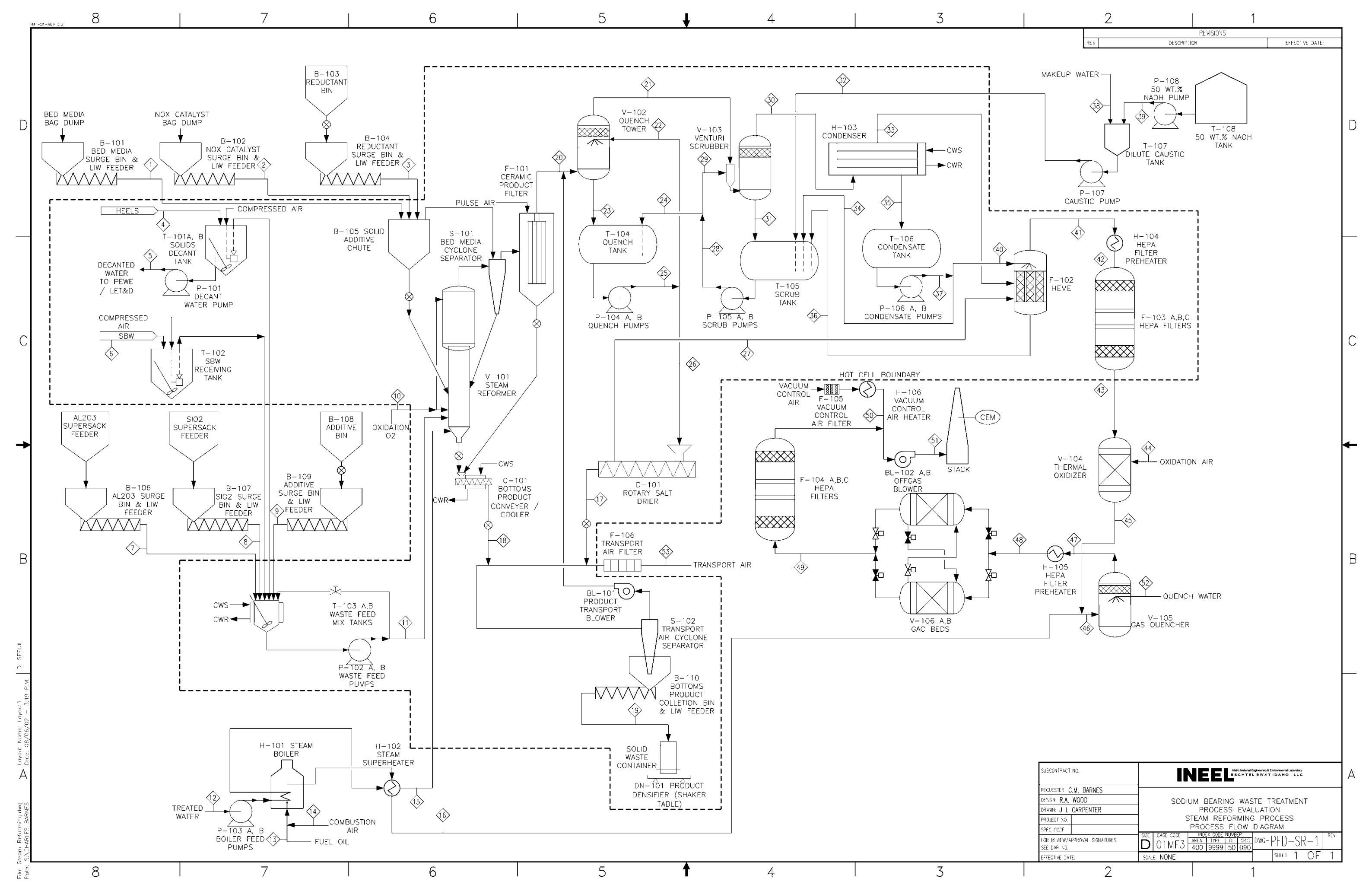



Calcination with MACT Upgrade 


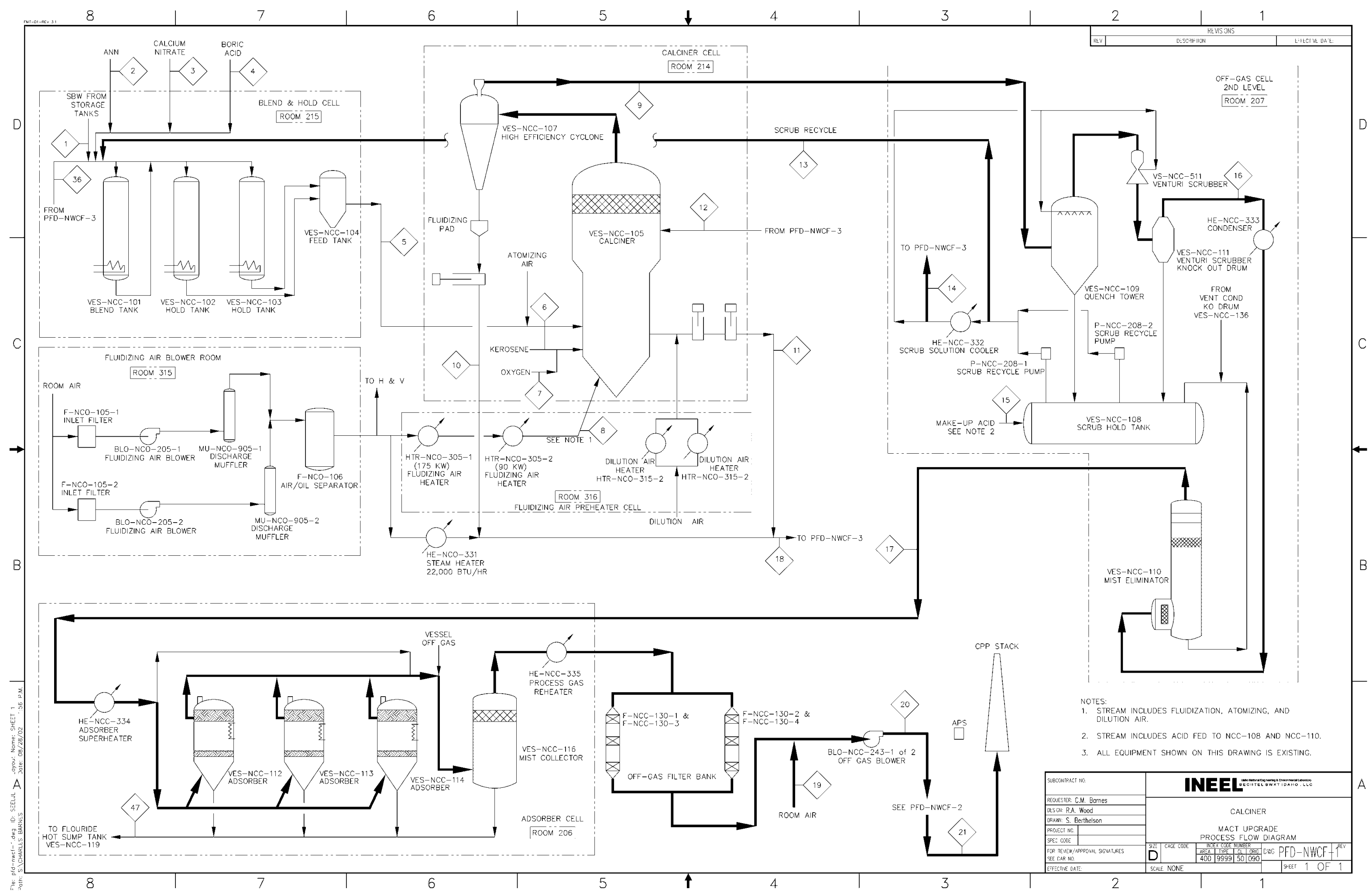





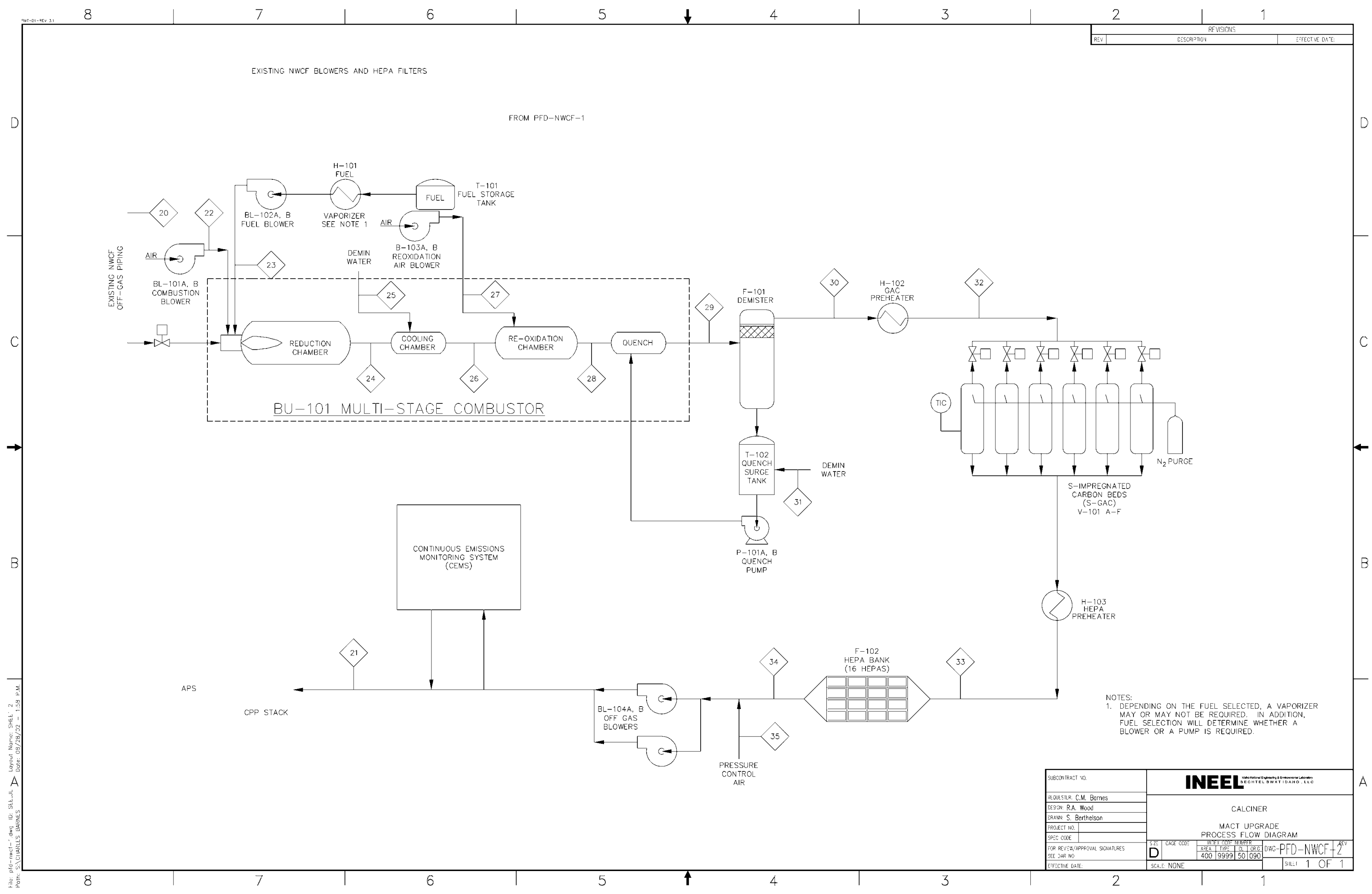

61 



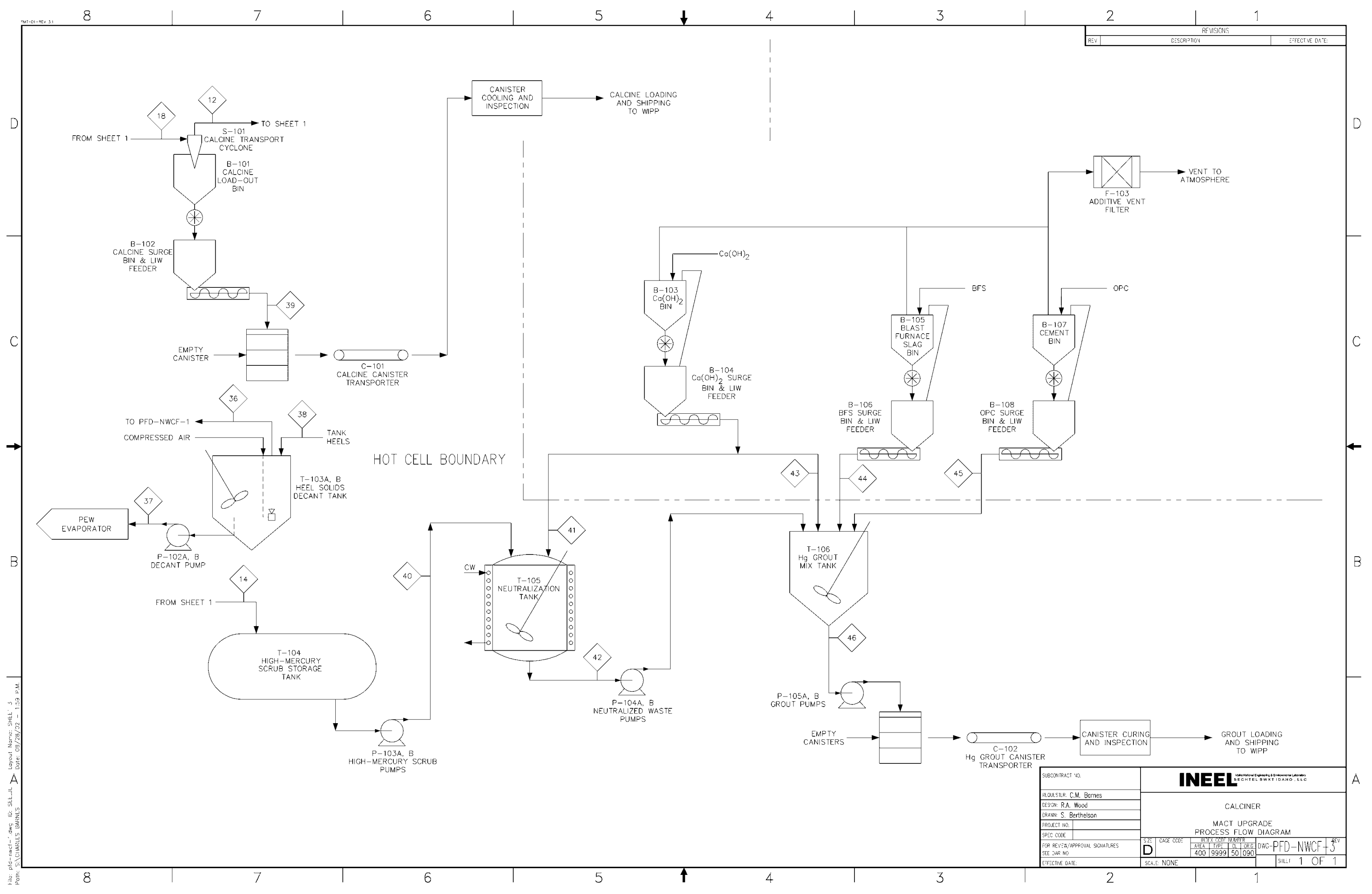



Cesium Ion Exchange with Immobilization 


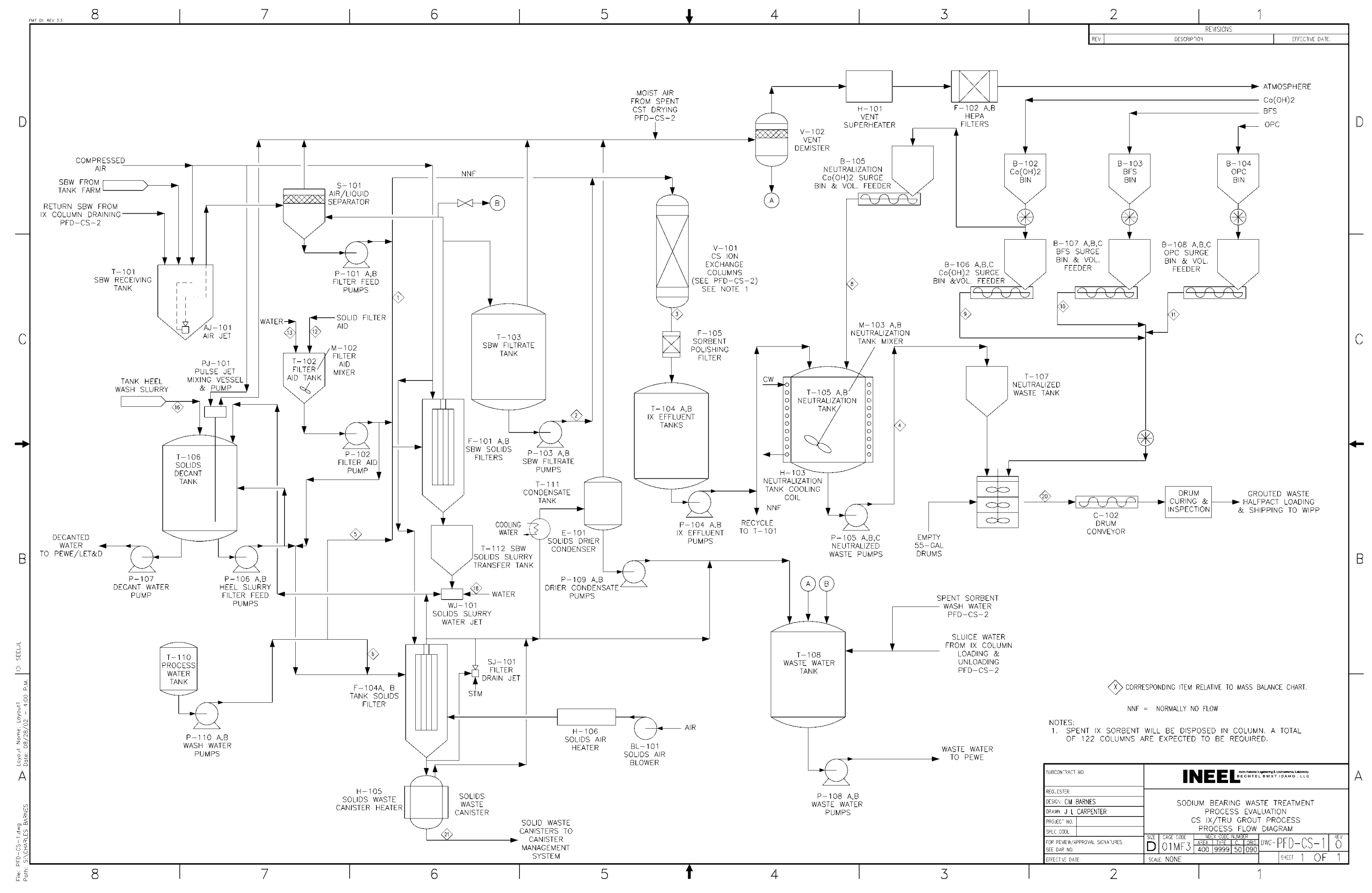





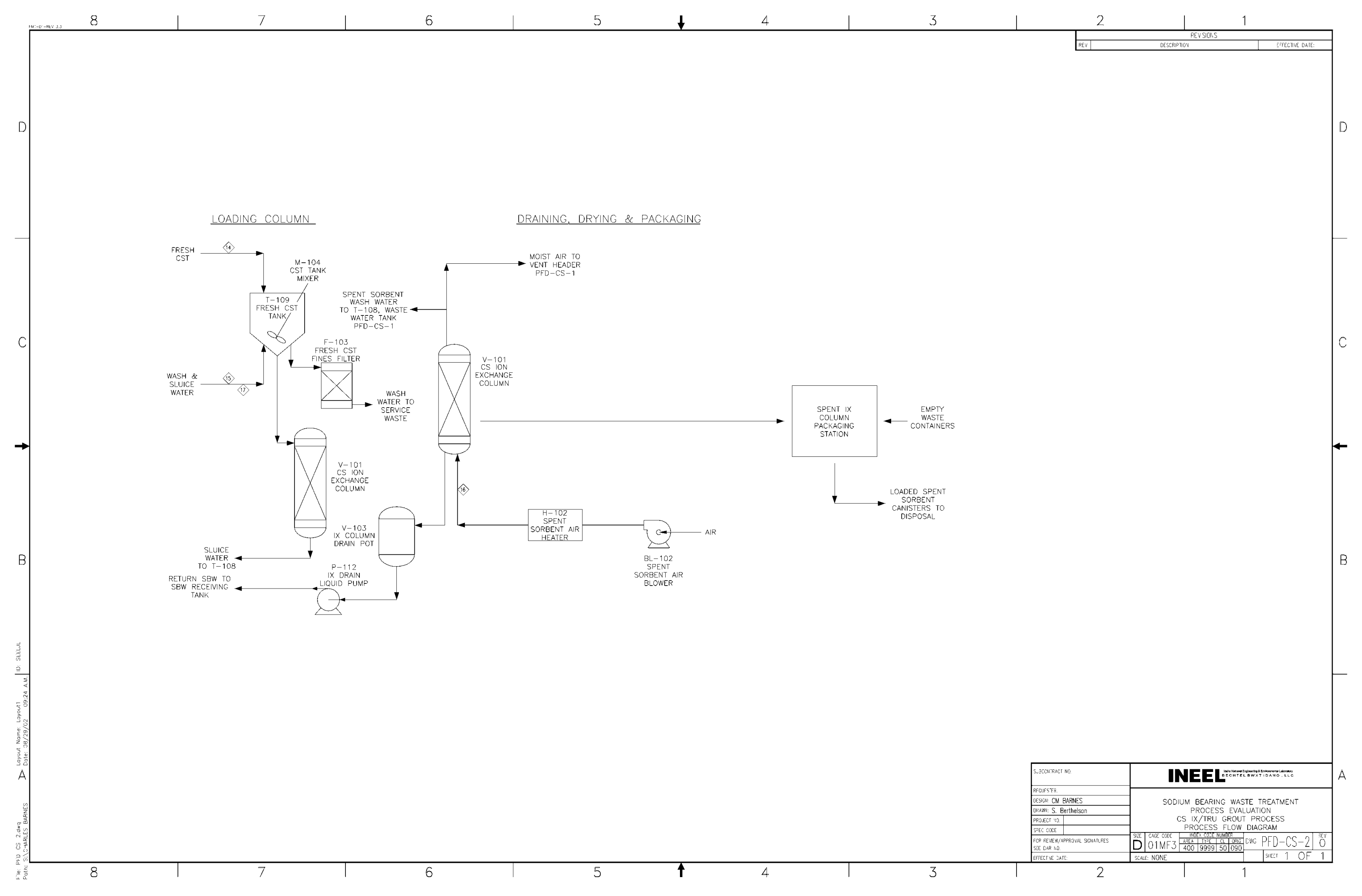



Direct Evaporation 


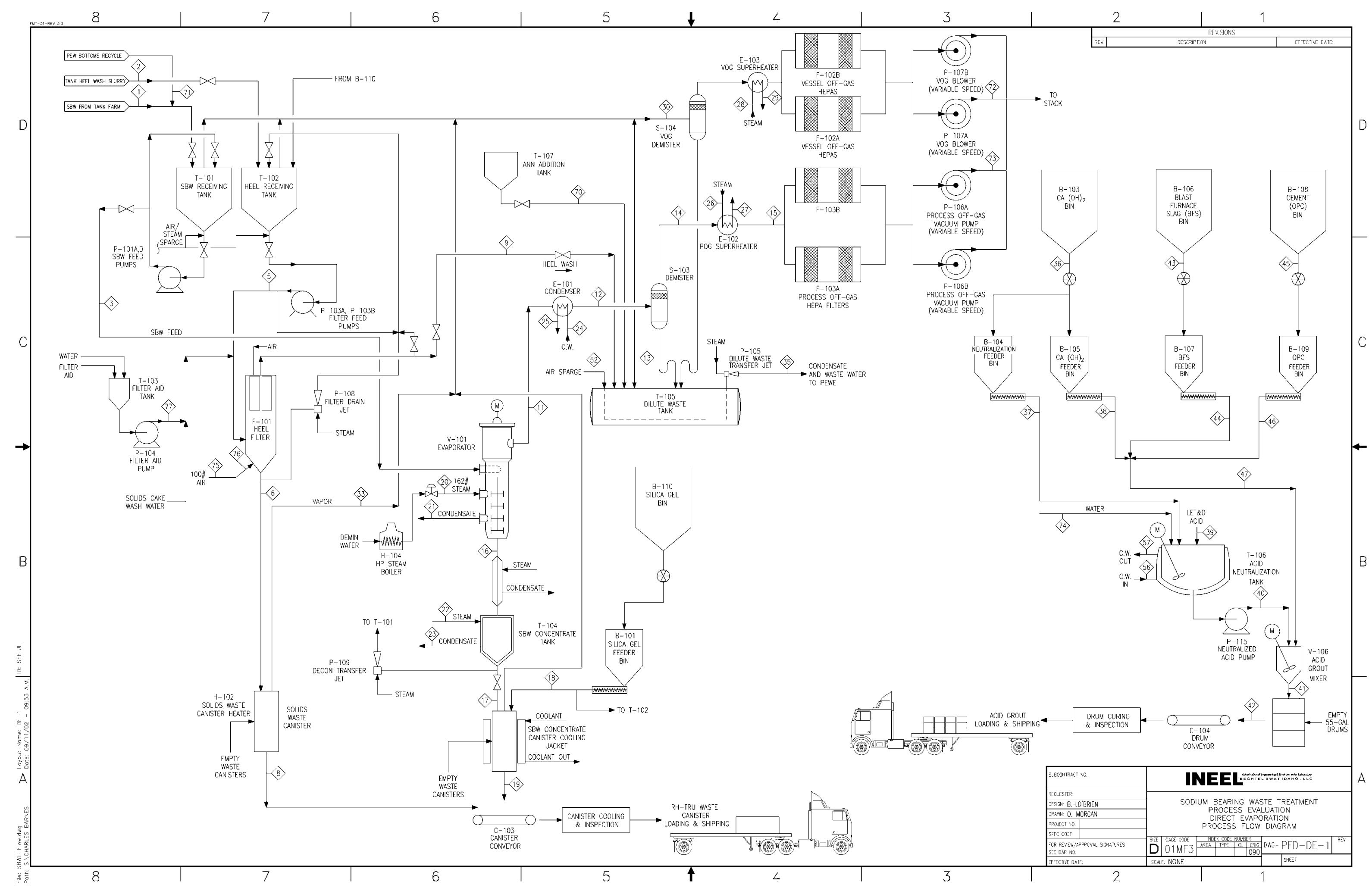

